\title{
High pressure studies of palladium and platinum thioether macrocyclic dihalide complexes
}

\author{
David R. Allan ${ }^{a^{*}}$, Daniel Bailey ${ }^{b}$, Nigel Bird ${ }^{b}$, Alexander J. Blake ${ }^{b_{*}}$, Neil R. Champness ${ }^{b_{*}}$, \\ Deguang Huang ${ }^{b}$, Conal P. Keane ${ }^{b}$, Jonathan McMaster $^{b_{*}}$, Timothy J. Prior ${ }^{c}$, Jeremiah P. \\ Tidey $^{b}$ and Martin Schröder ${ }^{b_{*}}$
}

aBeamline 119, Diamond Light Source, Harwell Science and Innovation Campus, Didcot, Oxfordshire, OX11 ODE, UK, 'S School of Chemistry, The University of Nottingham, University Park, Nottingham, Nottinghamshire, NG7 2RD, UK, and 'Department of Chemistry, University of Hull, Hull, HU6 7RX, UK

Correspondence email: a.j.blake@nottingham.ac.uk; neil.champness@nottingham.ac.uk; j.mcmaster@nottingham.ac.uk; m.schroder@nottingham.ac.uk

Keywords: High pressure; coordination complexes; palladium; platinum; macrocycle; intermolecular contacts; conformation; polymerisation

\section{Synopsis}

The behaviour under compression of a series of six isomorphous coordination complexes $\left[M X_{2}(1,4,7-\right.$ trithiacyclononane)] ( $M=\mathrm{Pd}, \mathrm{Pt} ; X=\mathrm{Cl}, \mathrm{Br}, \mathrm{I})$ is reported. The different structural properties of these complexes are described and analysed, including by the use of DFT and bond order calculations.

\section{Abstract}

The mononuclear macrocyclic $\mathrm{Pd}(\mathrm{II})$ complex cis- $\left[\mathrm{PdCl}_{2}\left([9] \mathrm{aneS}_{3}\right)\right]$ ([9]aneS $\mathrm{a}_{3}=1,4,7$-trithiacyclononane) converts at 44 kbar into an intensely coloured chain polymer exhibiting distorted octahedral co-ordination at the metal centre and an unprecedented [1233] conformation for the thioether ligand. The evolution of an intramolecular axial sulfur-metal interaction and an intermolecular equatorial sulfur-metal interaction is central to these changes. High pressure crystallographic experiments have also been undertaken on the related complexes $\left[\operatorname{PtCl}_{2}\left([9] \mathrm{aneS}_{3}\right)\right], \quad\left[\operatorname{PdBr}_{2}\left([9] \mathrm{aneS}_{3}\right)\right]$, $\left[\operatorname{PtBr}_{2}\left([9] \mathrm{aneS}_{3}\right)\right],\left[\operatorname{PdI}_{2}\left([9] \mathrm{aneS}_{3}\right)\right]$ and $\left[\operatorname{PtI}_{2}\left([9] \mathrm{aneS}_{3}\right)\right]$ in order to establish the effects of changing the halide ligands and the metal centre on the behaviour of these complexes under pressure. While all complexes undergo contraction of the various interaction distances with increasing pressure, only $\left[\mathrm{PdCl}_{2}\left([9] \mathrm{aneS}_{3}\right)\right]$ undergoes a phase change. Pressure-induced I ${ }^{\cdots} \mathrm{I}$ interactions were observed for 
$\left[\operatorname{PdI}_{2}\left([9] \mathrm{aneS}_{3}\right)\right]$ and $\left[\operatorname{PtI}_{2}\left([9] \mathrm{aneS}_{3}\right)\right]$ at $19 \mathrm{kbar}$ but the corresponding $\mathrm{Br}{ }^{*} \mathrm{Br}$ interactions in $\left[\operatorname{PdBr}_{2}\left([9] \mathrm{aneS}_{3}\right)\right]$ and $\left[\mathrm{PtBr}_{2}\left([9] \mathrm{aneS}_{3}\right)\right]$ only become significant at much higher pressure (58 kbar). Accompanying DFT calculations have yielded interaction energies and bond orders for the sulfurmetal interactions.

\section{Introduction}

The number of coordination complexes being studied under high pressure is increasing rapidly, and a search of the Cambridge Structural Database (Allen, 2002; CSD version 5.34 November 2012 plus three updates) reveals 214 entries for transition metal crystal structures determined above ambient pressure: 72 of these were published prior to 2009 commencing with the first report in 1989, with 70 in 2009-2010 and a further 72 published between 2011 and 2014. As each pressure point in a high pressure experiment is recorded in the CSD as a separate entry, the number of unique complexes studied is substantially lower, with currently $c a .50$ systems in the literature.

High pressure studies of organic compounds typically produce new phases by the rearrangement of their intermolecular interactions, with bonded distances and valence angles largely unaffected; in contrast coordination compounds, where the metal geometry and bond distances are more flexible, can exhibit changes in bond distances which are an order of magnitude greater than in organic compounds.

The majority of high pressure single-crystal diffraction studies on metal complexes have been performed to explore the compressibility of intermolecular and intramolecular interactions or to explore variations in physical properties such as magnetism (Parois et al., 2010; Prescimone et al., 2008, 2009); gas absorption (Takamizawa et al., 2005; Takamizawa \& Kohbara, 2007; Takamizawa et al., 2009), electrical conductivity (Okano et al., 2004; Guionneau et al., 1995; Rahal et al., 1997) and piezochromism (Bryne et al., 2012). In Fe(II) spin-crossover complexes, high-to-low-spin transitions have been reported for $\left[\mathrm{Fe}(\text { phen })_{2}(\mathrm{NCS})_{2}\right]$ and $\left[\mathrm{Fe}(\mathrm{Btz})_{2}(\mathrm{NCS})_{2}\right]$ (phen $=1,10-$ phenanthroline, Btz $=2,2^{\prime}$-bi-4,5-dihydrothiazine) at 10 and $5 \mathrm{kbar}$, respectively (Granier et al., 1993). Ambient conditions of pressure and temperature usually favour the high-spin state species in which occupation of antibonding $e_{\mathrm{g}}$ orbitals leads to these complexes having higher volumes. Increasing pressure thus favours the low-spin state configuration by minimising the $p V$ contribution to free energy.

A study of $\left.[\mathrm{GuH}]\left[\mathrm{Cu}_{2}(\mathrm{OH}) \text { (citrate)(guanidine }\right)_{2}\right](\mathrm{GuH}=$ guanidinium cation) by Moggach et al. (2009) illustrates the wide range of geometric changes possible for a metal coordination complex. The coordination at the $\mathrm{Cu}(\mathrm{II})$ centres changes from [4 +1$]$ distorted square pyramidal to [4+2] distorted octahedral as part of a phase change at $29.5 \mathrm{kbar}$, with one of the $\mathrm{Cu}$ (II) centres reverting to a [ $4+1]$ coordination mode on passing through a second phase change at $42.3 \mathrm{kbar}$. These changes involve conversions between long intermolecular interactions and coordinative bonds. The conversion of 
intramolecular and intermolecular interactions to full covalent or coordinate bonds remains rare at pressures below $100 \mathrm{kbar}$.

We previously reported (Allan et al., 2006) that $\left[\mathrm{PdCl}_{2}\left([9] \mathrm{aneS}_{3}\right)\right]$, a mononuclear square-planar Pd(II) complex, undergoes a second-order phase transition at 44 kbar: the geometry becomes distorted octahedral via short S...Pd interactions, a chain polymer is formed with a new macrocyclic conformation, and the colour of the complex changes dramatically from orange to black. The observation of this array of phenomena led us to investigate further $\left[\mathrm{PdCl}_{2}\left([9] \mathrm{aneS}_{3}\right)\right]$ and five closely-related complexes, described herein.

\section{Experimental}

\subsection{Synthesis}

\subsection{1. cis-Dichloro(1,4,7-trithiacyclononane)palladium(II) ([ $\left.\left.\mathrm{PdCl}_{2}\left([9] \mathrm{aneS}_{3}\right)\right]\right)$}

The complex was prepared according to a published procedure (Blake et al., 1988; Blake et al., 1996). Crystals were obtained from a solution of the complex in $\mathrm{CH}_{3} \mathrm{NO}_{2}$.

\subsection{2. cis-Dichloro(1,4,7-trithiacyclononane)platinum(II) $\left(\left[\mathrm{PtCl}_{2}\left([9] \mathrm{aneS}_{3}\right)\right]\right)$}

The complex was prepared according to the procedure described by Grant et al. (2001). Crystals were obtained from a solution of the complex in $\mathrm{CH}_{3} \mathrm{NO}_{2}$.

\subsection{3. cis-Dibromo(1,4,7-trithiacyclononane)palladium(II) $\left(\left[\mathrm{PdBr}_{2}\left([9] \mathrm{laneS}_{3}\right)\right]\right)$}

$\left[\mathrm{PdBr}_{2}\left([9] \mathrm{aneS}_{3}\right)\right]$ was synthesised by adding a mixture of $\operatorname{PdBr}_{2}(0.080 \mathrm{~g}, 0.300 \mathrm{mmol})$ and [9]aneS $\mathrm{S}_{3}$ ([9]aneS $\mathrm{a}_{3}=1,4,7$-trithiacyclononane; $\left.0.054 \mathrm{~g}, 0.300 \mathrm{mmol}\right)$ and then refluxed in $\mathrm{CH}_{3} \mathrm{CN}_{\mathbf{C}} \mathrm{CH}_{2} \mathrm{Cl}_{2}(3: 1$ v/v, $25 \mathrm{ml}$ ) for 48 h. IR $\left(\mathrm{KBr} / \mathrm{cm}^{-1}\right)$ : 2958 (w), 2933 (w), 1631 (broad m), 1438 (m), 1384 (s), 1146 (m), $936(\mathrm{~m}), 888(\mathrm{~m}), 835(\mathrm{~m}), 806(\mathrm{~m}) .{ }^{1} \mathrm{H}$ NMR (DMSO- $\left.d_{6}\right): \delta=40.0 \mathrm{ppm}$. FAB MS: $m / z 366$ for $\left[\operatorname{PdBr}_{2}\left([9] \mathrm{aneS}_{3}\right)\right]^{+}$. Crystals were grown by slow diffusion of diethyl ether vapour into a solution of the complex in DMSO.

\subsection{4. cis-Dibromo(1,4,7-trithiacyclononane)platinum(II) ([PtBr $\left.\left.2\left([9] a n e S_{3}\right)\right]\right)$}

$\left[\mathrm{PtBr}_{2}\left([9] \mathrm{aneS}_{3}\right)\right]$ was synthesised as described by Grant et al. (2001). IR $\left(\mathrm{KBr} / \mathrm{cm}^{-1}\right): 2959$ (w), 1635 (broad m), 1438 (m), 1384 (s), 1146 (m), 936 (m), 888 (m), 835 (m), 806 (m) cm ${ }^{-1} .{ }^{1}$ H NMR (DMSO$\left.d_{6}\right): \delta=3.4 \mathrm{ppm}$ and ${ }^{13} \mathrm{C}$ NMR (DMSO- $\left.d_{6}\right): \delta=40.0 \mathrm{ppm}$. Crystals were grown by diffusion of diethyl ether vapour into a solution of the complex in DMSO.

\subsection{5. cis-Diiodo(1,4,7-trithiacyclononane)palladium(II) $\left(\left[\mathrm{Pdl}_{2}\left([9] \mathrm{aneS}_{3}\right)\right]\right)$}


$\left[\operatorname{PdI}_{2}\left([9] \mathrm{aneS}_{3}\right)\right]$ was synthesised by dissolving cis- $\left[\mathrm{PdCl}_{2}\left([9] \mathrm{aneS} \mathrm{S}_{3}\right)\right](50 \mathrm{mg}, 0.14 \mathrm{mmol})$ and $\mathrm{NaI}(42$ $\mathrm{mg}, 0.28 \mathrm{mmol})$ in acetone $\left(10 \mathrm{~cm}^{3}\right)$. The solution was stirred for $24 \mathrm{~h}$; an orange solution was formed and the solid washed with water and acetone and left to dry overnight to give a yellow solid $(0.024 \mathrm{~g}$, yield 31.7\%). ${ }^{1} \mathrm{H}$ NMR (270 MHz, $\left.\mathrm{CDCl}_{3}\right): \delta=2.68 \mathrm{ppm}(\mathrm{s}, 12 \mathrm{H}) ;{ }^{13} \mathrm{C} \mathrm{NMR}\left(\mathrm{CDCl}_{3}\right): \delta=118.25$ ppm. FAB MS: $m / z=563$ for $\left[\operatorname{PdI}_{2}\left([9] \mathrm{aneS}_{3}\right)\right]^{+} \mathrm{Na}^{+}$. Crystals were grown by dissolving the yellow microcrystalline product in the minimum amount of hot acetonitrile and allowing the resulting solution to cool slowly over a period of $48 \mathrm{~h}$.

\subsection{6. cis-Diiodo(1,4,7-trithiacyclononane)platinum(II) $\left(\left[\mathrm{Ptl}_{2}\left([9] \mathrm{aneS}_{3}\right)\right]\right)$}

$\left[\operatorname{PtI}_{2}\left([9] \mathrm{aneS}_{3}\right)\right]$ was prepared by first synthesising $\left[\mathrm{PtCl}_{2}\left([9] \mathrm{aneS}_{3}\right)\right]$ and then converting it to $\left[\mathrm{PtI}_{2}\left([9] \mathrm{aneS}_{3}\right)\right]$. $\left[\mathrm{PtCl}_{2}\left([9] \mathrm{aneS}_{3}\right)\right]$ was synthesised by adding cis-bis(acetonitrile)dichloroplatinum(II) $(0.2394 \mathrm{~g}, 0.08 \mathrm{mmol})$ and $[9] \mathrm{aneS}_{3}(0.16 \mathrm{~g}, 0.89 \mathrm{mmol})$ to a mixture of acetonitrile $(100 \mathrm{~mL})$ and dichloromethane $(25 \mathrm{~mL})$. The mixture was then refluxed overnight to give an orange precipitate. This precipitate was washed with acetone and water and left to dry overnight. $\left[\mathrm{PtCl}_{2}\left([9] \mathrm{aneS} \mathrm{S}_{3}\right)\right]$ $(0.1077 \mathrm{~g}, 0.024 \mathrm{mmol})$ and $\mathrm{NaI}(0.0724 \mathrm{~g}, 0.048 \mathrm{mmol})$ were dissolved in acetonitrile $(100 \mathrm{~mL})$. The solution was stirred for $24 \mathrm{~h}$ after which an orange solution was formed and the solid washed with water and acetone and left to dry overnight to give an orange solid $(0.199 \mathrm{~g}, 76 \%$ yield $) .{ }^{1} \mathrm{H}$ NMR $\left(\mathrm{CDCl}_{3}\right): \delta=2.70 \mathrm{ppm}(\mathrm{s}, 12 \mathrm{H}) ;{ }^{13} \mathrm{C} \mathrm{NMR}\left(\mathrm{CDCl}_{3}\right): \delta=118.25 \mathrm{ppm}$. Elemental analysis found $\mathrm{C}=$ 11.95, $\mathrm{H}=1.85 \%$; Calculated for $\mathrm{C}_{6} \mathrm{H}_{12} \mathrm{~S}_{3} \mathrm{PtI}_{2}: \mathrm{C}=11.45, \mathrm{H}=1.92 \%$; FAB MS: $m / z=651$ for $\left[\operatorname{PtI}_{2}\left([9] \mathrm{aneS}_{3}\right)\right]^{+} \mathrm{Na}^{+}$. Crystals were grown as for $\left[\mathrm{PdI}_{2}\left([9] \mathrm{aneS}_{3}\right)\right]$.

\subsection{High pressure studies}

A Merrill-Bassett diamond anvil cell (DAC) was constructed around Boehler-Almax diamonds with $600 \mu \mathrm{m}$ culets. Laser-cut tungsten (Goodfellow Metals, thickness $200 \mu \mathrm{m}$ ) was used as the gasket material, and gasket holes (200 $\mu \mathrm{m}$ diameter) were drilled using a BETSA electric discharge machine. A crystal was placed in the DAC along with a ruby sphere for pressure measurement and $4: 1$ methanol/ethanol as the pressure transmitting medium (PTM). The pressure was allowed to equilibrate for at least one hour after each ramp before being measured using the ruby fluorescence method (Barnett et al., 1973). The pressure was re-measured immediately after the frameset was collected and the average pressure calculated. Although individual pressure measurements were reproducible to within $0.5 \mathrm{kbar}$ (Holzapfel, 2003), the pressure drifted slightly during the collection of the frames, with the result that average pressures are subject to an uncertainty of 2 kbar. A pressure of 0.001 kbar corresponds to atmospheric pressure: the crystal and the ruby are loaded into the DAC but no PTM has yet been added.

\subsection{1. $\left[\mathrm{PdCl}_{2}\left([9] \mathrm{ane} \mathrm{S}_{3}\right)\right]$}


Measurements were conducted at Daresbury Synchrotron Radiation Source Station 16.2SMX on two crystals of $\left[\mathrm{PdCl}_{2}\left([9] \mathrm{aneS}_{3}\right)\right]$, each of dimensions $0.15 \times 0.15 \times 0.05 \mathrm{~mm}$, using a Bruker APEXII CCD area detector, with a wavelength of $0.8406 \AA$. Framesets were collected at the following pressures: $0.001,12.6,23.5,36,48.7,73.1,76.8$ and $53.5 \mathrm{kbar}$ for crystal 1; 46.0 and $42.5 \mathrm{kbar}$ for crystal 2. Cell refinement and data reduction was completed using Bruker SAINT (Bruker, 2002). Structure solution used SHELXS97 (Sheldrick, 2008), absorption corrections were applied by means of multi-scan methods (SADABS; Sheldrick, 2004), structure refinement used SHELXL97 (Sheldrick, 2008) and molecular graphics used PLATON (Spek, 2009). Because the completeness of the data was severely restricted by the geometry of the diamond anvil cell, only $\mathrm{Pd}, \mathrm{Cl}$ and $\mathrm{S}$ atoms could be refined anisotropically, even with the use of suitable restraints. This occurs even at lower pressures; with increasing pressure, more atoms were refined isotropically; at the highest pressure all atoms were refined isotropically (see CIFs and Table ED1 in Supplementary Information).

\subsection{2. $\left[\mathrm{PtCl}_{2}\left([9] \mathrm{aneS}_{3}\right)\right]$}

Diffraction data were acquired from crystals 1 and 2 of $\left[\mathrm{PtCl}_{2}\left([9] \mathrm{aneS}_{3}\right)\right]$ at Daresbury SRS Station 16.2SMX and from crystal 3 at Diamond Light Source Beamline I19. The SRS experiments (at pressures of $0.001,16.3,32.7,41.9$ and $54.0 \mathrm{kbar}$ for crystal 1 and 28.8 and 37.8 kbar for crystal 2) utilised a Bruker APEXII CCD area detector and a three-circle goniometer, with a synchrotron wavelength of $0.6911 \AA$ (crystal 1) or $0.8004 \AA$ (crystal 2). Cell refinement and data reduction, structure solution and structure refinement were completed as above for $\left[\mathrm{PdCl}_{2}\left([9] \mathrm{aneS}_{3}\right)\right]$.

Framesets for crystal 3 were acquired on Diamond Beamline I19, at 3.0, 21.8 and $47.1 \mathrm{kbar}$ using a Rigaku Saturn 724 CCD area detector and a CrystalLogic 4-circle kappa goniometer, using a synchrotron wavelength of $0.6889 \AA$. Cell refinement and data reduction were completed using CrysAlis Pro (Agilent, 2011) and absorption corrections, structure solution and refinement used the same programs as above for $\left[\mathrm{PdCl}_{2}\left([9] \mathrm{aneS}_{3}\right)\right]$. Despite the limited completeness of the data all non-H atoms could be refined anisotropically with the application of suitable extensive restraints to molecular geometry and displacement parameters (see CIFs and Table ED2 in Supplementary Information).

\subsection{3. $\left[\mathrm{PdBr}_{2}([9] \mathrm{aneS})\right]$}

Framesets were obtained at Diamond Light Source Beamline I19 as for $\left[\mathrm{PtCl}_{2}\left([9] \mathrm{aneS}_{3}\right)\right]$ on a brown block of $\left[\operatorname{PdBr}_{2}\left([9] \mathrm{aneS}_{3}\right)\right]$ measuring $0.14 \times 0.09 \times 0.07 \mathrm{~mm}$. Framesets were collected at the following pressures: 0.001, 4.6, 25.0, 102.6, 64.7, 50.1, 40.1, 30.4, 96.5, 71.3, 81.9, 116.9 kbar. Cell refinement, data reduction, absorption corrections, structure solution and structure refinement were carried out as for $\left[\mathrm{PtCl}_{2}\left([9] \mathrm{aneS}_{3}\right)\right]$. At lower pressures, non-H atoms could be refined anisotropically with the application of suitable extensive restraints to molecular geometry and displacement 
parameters (see CIFs and Table ED3 in Supplementary Information); at higher pressures only isotropic refinement (with geometric restraints) was possible.

\subsection{4. $\left[\mathrm{PtBr}_{2}([9] \mathrm{aneS})\right]$}

Diffraction data for $\left[\mathrm{PtBr}_{2}\left([9] \mathrm{aneS}_{3}\right)\right]$ were taken at Diamond Light Source Beamline I19 as for $\left[\mathrm{PtCl}_{2}\left([9] \mathrm{aneS}_{3}\right)\right]$ on a red/brown block measuring $0.10 \times 0.10 \times 0.15 \mathrm{~mm}$. Framesets were collected at the following pressures: 0.001, 2.7, 17.0, 42.5, 62.5, 74.9, 82.6, 88.8, 97.1, 48.2 and 32.7 kbar. Cell refinement, data reduction, absorption corrections, structure solution and structure refinement were carried out as for $\left[\mathrm{PtCl}_{2}\left([9] \mathrm{aneS}_{3}\right)\right]$. At all pressures, non-H atoms could be refined anisotropically with the application of suitable extensive restraints to molecular geometry and displacement parameters (see CIFs and Table ED4 in Supplementary Information).

\subsection{5. $\left[\mathrm{Pdl}_{2}\left([9] \mathrm{ane} \mathrm{S}_{3}\right)\right]$}

Framesets for $\left[\operatorname{PdI}_{2}\left([9] \mathrm{aneS}_{3}\right)\right]$ were acquired at Diamond Light Source Beamline I19 as for $\left.\mathrm{PtCl}_{2}\left([9] \mathrm{aneS}_{3}\right)\right]$ on a dark red block measuring $0.10 \times 0.10 \times 0.15 \mathrm{~mm}$. Framesets were collected at the following pressures: 0.001, 7.6, 19.0, 30.0, 57.7, 36.6, 60.4, 79.4, 94.0, 66.2 and 41.9 kbar. Cell refinement, data reduction, absorption corrections, structure solution and structure refinement were carried out as for $\left[\mathrm{PtCl}_{2}\left([9] \mathrm{aneS}_{3}\right)\right]$. No restraints were required to allow anisotropic refinement against data acquired at ambient pressure, but at all other pressures extensive restraints to molecular geometry and displacement parameters were required (see CIFs and Table ED5 in Supplementary Information).

\subsection{6. $\left[\mathrm{Ptl}_{2}\left([9] \mathrm{ane} \mathrm{S}_{3}\right)\right]$}

Framesets were taken at Diamond Light Source Beamline I19 as for $\left.\mathrm{PtCl}_{2}\left([9] \mathrm{aneS}_{3}\right)\right]$ on a dark red block of $\left[\operatorname{PtI}_{2}\left([9] \mathrm{aneS}_{3}\right)\right]$ measuring $0.10 \times 0.10 \times 0.15 \mathrm{~mm}$. Framesets were collected at the following pressures: $0.001,6.0,23.8,38.0,48.8,55.8,61.3$ and 69.7 kbar. Cell refinement, data reduction, absorption corrections, structure solution and structure refinement were carried out as for $\left[\mathrm{PtCl}_{2}\left([9] \mathrm{aneS}_{3}\right)\right]$. Anisotropic refinement required the use of extensive restraints at all pressures (see CIFs and Table ED6 in Supplementary Information). The Flack (1983) parameter was allowed to refine to values $>0.5$ without the structure being inverted in order to allow direct comparison of the ligand conformations at different pressures.

\subsection{DFT Calculations}

Single point DFT calculations were performed on models derived from the high pressure crystal structure determinations on $\left[M X_{2}\left([9] \mathrm{aneS}_{3}\right)\right](M=\mathrm{Pd}, \mathrm{Pt} ; X=\mathrm{Cl}, \mathrm{Br}, \mathrm{I})$. For each complex and pressure, two symmetry-equivalent molecules were generated to give a chain of three molecules along 
the direction of the intermolecular $M \cdots \mathrm{S} 4$ interaction. The calculations were performed using the Amsterdam Density Functional (ADF) suite version 2007.01 (Fonseca-Guerra et al., 1998; Te Velde et al., 2001). The DFT geometry optimisations employed Slater-type orbital (STO) triple- $\zeta$-plus polarisation all-electron basis sets (from the ZORA/TZP database of the ADF suite). Scalar relativistic approaches were used within the ZORA Hamiltonian for the inclusion of relativistic effects and the local density approximation (LDA) with the correlation potential due to Vosko et al. (1980) was used in all of the calculations. Gradient corrections were performed using the functionals of Becke (1998) and Perdew (1986).

\section{Results}

\subsection{Effects of pressure on unit cell parameters}

Additional Figures showing the effects of pressure on unit cell parameters appear in Appendix A of the Supplementary Data: only the most significant features are described here. The molecules which eventually form extended chains are related by the $2_{1}$ screw axis parallel to the crystallographic $a$ axis.

\subsection{1. $\left[\mathrm{PdCl}_{2}([9] \mathrm{aneS})\right]$}

During the abrupt phase change at 44 kbar (see below) the decreasing length of the $c$ axis of $\left[\mathrm{PdCl}_{2}\left([9] \mathrm{aneS}_{3}\right)\right]$ is reversed: it increases by $0.1594(13) \AA$ and this, along with the continuing decrease in the $b$ axis, causes the lengths of these axes to cross over (Table 1, Figure 1). Between ambient pressure and $76.8 \mathrm{kbar}$ the unit cell volume decreases by $23.5 \%$, from $1128.2(4)$ to $869.6(2)$ $\AA^{3}$, with similar contractions of $8.5 \%$ and $9.0 \%$ for the $a$ and $b$ axes, respectively, and a slightly lower value of $7.4 \%$ for the $c$ axis. Between 42.5 and $46.0 \mathrm{kbar}$, i.e., at pressures bracketing the phase change at $44 \mathrm{kbar}$, the unit cell volume contracts by $14.5(7) \AA^{3}$.

Table 1 Variations in unit cell parameters for $\left[\mathrm{PdCl}_{2}\left([9] \mathrm{aneS}_{3}\right)\right]$.

\begin{tabular}{|c|c|c|c|c|}
\hline Pressure/kbar & $a / \AA$ & $b / \AA$ & $c / \AA$ & $V / \AA^{3}$ \\
\hline ambient & $7.5626(11)$ & $12.1894(15)$ & $12.239(4)$ & $1128.2(4)$ \\
\hline 12.6 & $7.3362(8)$ & $11.9411(11)$ & $11.864(3)$ & $1039.3(3)$ \\
\hline 23.5 & $7.2357(9)$ & $11.8141(12)$ & $11.692(3)$ & $999.5(3)$ \\
\hline 36.0 & $7.152(2)$ & $11.695(2)$ & $11.553(4)$ & $966.3(5)$ \\
\hline 42.5 & $7.0777(12)$ & $11.601(8)$ & $11.4241(10)$ & $938.0(7)$ \\
\hline 46.0 & $7.0624(12)$ & $11.2892(12)$ & $11.5835(9)$ & $923.5(2)$ \\
\hline 53.5 & $7.0324(8)$ & $11.223(3)$ & $11.5032(11)$ & $907.9(2)$ \\
\hline 73.1 & $6.9416(9)$ & $11.116(3)$ & $11.3535(13)$ & $876.0(3)$ \\
\hline 76.8 & $6.9234(9)$ & $11.089(2)$ & $11.3268(11)$ & $869.6(2)$ \\
\hline
\end{tabular}

\subsubsection{Variations in unit cell parameters for the six complexes}


In contrast to $\left[\mathrm{PdCl}_{2}\left([9] \mathrm{ane} \mathrm{S}_{3}\right)\right]$, the unit cell volumes of the other five complexes tend to decrease smoothly with increasing pressure, and provide no indications of a phase change in a wide pressure range around $44 \mathrm{kbar}$ (Table 2). The relative contractions in the lengths of the $a$ and $b$ axes tend to be somewhat similar, but they are consistently larger than the reductions in the $c$ axis lengths. There are no simple correlations between the relative variations in unit cell dimensions and the pressure-induced structural changes in the complexes: we tentatively attribute this absence to the fact that multiple intramolecular and intermolecular changes take place concomitantly. The calculated bulk moduli in Table 2 are typical of molecular complexes (Tidey et al., 2014 and references therein) but the standard uncertainties preclude the identification of any meaningful trends.

Table 2 Variations in unit cell parameters and bulk moduli for the six complexes as a function of pressure

\begin{tabular}{|c|c|c|c|c|c|c|}
\hline Complex & Pressure/kbar & $\begin{array}{c}\text { Reduction } \\
\text { in a/\% }\end{array}$ & $\begin{array}{c}\text { Reduction } \\
\text { in } b / \%\end{array}$ & $\begin{array}{c}\text { Reduction } \\
\text { in c/\% }\end{array}$ & $\begin{array}{c}\text { Reduction } \\
\text { in } V / \%\end{array}$ & $\begin{array}{c}\text { Bulk } \\
\text { modulus/GPa }\end{array}$ \\
\hline$\left[\mathrm{PdCl}_{2}\left([9] \mathrm{aneS}_{3}\right)\right]$ & $0-76.8$ & 8.5 & 9.0 & 7.4 & 23.5 & $12.8(13)$ \\
\hline$\left[\mathrm{PdCl}_{2}\left([9] \mathrm{aneS}_{3}\right)\right]$ & $0-42.5$ & 6.4 & 4.8 & 6.7 & 16.9 & $13(3)$ \\
\hline$\left[\mathrm{PdCl}_{2}\left([9] \mathrm{aneS}_{3}\right)\right]$ & $46.0-76.8$ & 2.1 & 4.2 & 0.7 & 6.6 & $\ddagger$ \\
\hline$\left[\mathrm{PtCl}_{2}\left[[9] \mathrm{aneS}_{3}\right)\right]$ & $0-54.0$ & 7.0 & 7.3 & 5.6 & 18.7 & $12(2)$ \\
\hline$\left[\mathrm{PdBr}_{2}\left([9] \mathrm{aneS}_{3}\right)\right]$ & $0-116.9$ & 9.4 & 10.2 & 7.6 & 24.0 & $16(2)$ \\
\hline$\left[\mathrm{PtBr}_{2}\left([9] \mathrm{aneS}_{3}\right)\right]$ & $0-97.1$ & 8.3 & 10.4 & 6.7 & 24.8 & $10.8(17)$ \\
\hline$\left[\mathrm{PdI}_{2}\left[[9] \mathrm{aneS}_{3}\right)\right]$ & $0-94.0$ & 8.3 & 9.4 & 8.3 & 24.0 & $8.4(15)$ \\
\hline$\left[\mathrm{PtI}_{2}\left([9] \mathrm{aneS}_{3}\right)\right]$ & $0-69.7$ & 8.4 & 8.7 & 6.0 & 21.0 & $8(2)$ \\
\hline
\end{tabular}

${ }^{\dagger}$ Calculated using EosFit7c (Angel et al., 2014); ${ }^{*}$ insufficient data for a reliable fit

\subsection{Effects of pressure on the molecular geometry of $\left[\mathrm{PdCl}_{2}([9] \mathrm{aneS})\right]$}

\subsubsection{The structure of $\left[\mathrm{PdCl}_{2}\left([9] a n e S_{3}\right)\right]$ at ambient pressure}

The complex crystallises in the chiral orthorhombic space group $P 2_{1} 2_{1} 2_{1}$ with $a=7.5626(11), b=$ 12.1894(15), $c=12.239(9) \AA$ and $V=1128.2(4) \AA^{3}$ (Blake et al., 1988). At ambient pressure the $\mathrm{Pd}(\mathrm{II})$ centre (Pd1) is surrounded by a distorted square planar arrangement of two cis-coordinating sulfur atoms (S4 and S7) at 2.250(4) and 2.261(6) A, respectively, and two chloride ions (Cl1 and $\mathrm{Cl} 2$ ) at 2.331(7) and 2.325(4) A, respectively (Figure 2). The apical sulfur atom (S1) participates in a $\operatorname{Pd} 1 \cdots \mathrm{S} 1$ interaction of 3.140(2) Å: this value lies within the sum of the van der Waals radii $\left(\Sigma_{\mathrm{vdw}}\right)$ for Pd and S (3.43 Å; Bondi, 1964). The coordination around Pd1 is best described as [4+1], with the base comprising S4, S7, C11 and Cl2 and S1at the apex. Pd1 lies 0.099(5) A out of the plane defined by the two sulfur and two chloride donor atoms, in the direction of S1. The [9]aneS $S_{3}$ macrocycle is endodentate to Pd1 and adopts a [234] conformation with Dale corners (Dale, 1973) located at the 
atoms C3, C5 and C8. The apical sulfur atom S1 does not occupy a completely symmetrical position above the metal centre and relative to the two equatorial sulfur atoms, as shown by the different

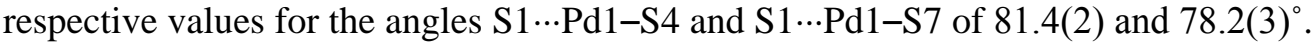

\subsubsection{Overview of the high pressure study of $\left[\mathrm{PdCl}_{2}\left([9] a n e S_{3}\right)\right]$}

The stimulus for the work described herein was provided by a high pressure study on cis$\left[\mathrm{PdCl}_{2}\left([9] \mathrm{aneS}_{3}\right)\right]$ (Allan et al., 2006). [ $\left.\mathrm{PdCl}_{2}\left([9] \mathrm{aneS}_{3}\right)\right]$ was originally chosen for study as the longrange apical $\mathrm{Pd} \cdots \mathrm{S}$ distance was expected to provide an especially sensitive indicator of the effects of pressure. It had already been shown that changing the ancillary ligands can affect the apical $\mathrm{Pd} \cdots \mathrm{S}$ distance in $\operatorname{Pd}(\mathrm{II})$ complexes of $[9] \mathrm{aneS}_{3}$, with $\pi$-donor ligands giving longer distances such as

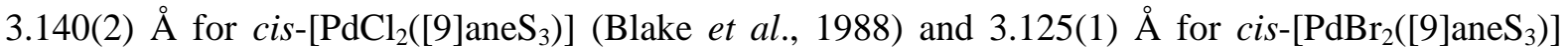
(Wieghardt et al., 1986), while $\pi$-acceptor ligands give much shorter distances such as 2.698(3) $\AA$ for

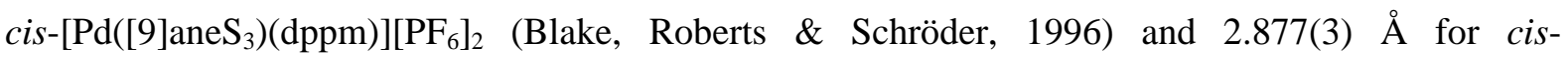
$\left[\mathrm{Pd}\left([9] \mathrm{aneS}_{3}\right)\left(\mathrm{PPh}_{3}\right)_{2}\right]\left[\mathrm{PF}_{6}\right]_{2}$ (Blake, Roberts \& Schröder, 1996; Wong et al., 2013). These apical distances bracket the value of 2.952(4) $\AA$ in the sandwich complex $\left[\mathrm{Pd}\left([9] \mathrm{aneS}_{3}\right)_{2}\right]\left[\mathrm{PF}_{6}\right]_{2}$ (Wieghardt et al., 1986; Blake et al., 1987), demonstrating facile electronic tuning of the apical Pd $\cdots \mathrm{S}$ distance. We now turned our attention to the question of whether the elongation of this distance by $\pi$-donor ligands could be neutralised or overcome by the application of high pressure.

At ambient pressure $\left[\mathrm{PdCl}_{2}\left([9] \mathrm{aneS}_{3}\right)\right]$ is an orange, square planar, mononuclear complex which at 44 kbar transforms into an intensely-black chain polymer with a distorted octahedral co-ordination at the metal centre. This phase transformation also involves a number of other structural changes to the complex: the distance between the apical sulfur atom and the Pd(II) metal centre contracts sharply; the aforementioned chain polymer is formed by the shortening of an interaction between each $\operatorname{Pd}(\mathrm{II})$ centre and an $\mathrm{S}$ atom on an adjacent molecule. Finally, the macrocyclic ring undergoes significant conformational changes. These changes are analysed more fully in the following sections, but it is relevant to note here than the phase transformation appears to be fully reversible, with little or no hysteresis: reducing the pressure below 44 kbar restores the original mononuclear orange complex. Packing diagrams for the $\left[\mathrm{PdCl}_{2}\left([9] \mathrm{aneS}_{3}\right)\right]$ structure at $0.001,42.5,46.0$ and $76.8 \mathrm{kbar}$ appear as Supplementary Figures P1-P4.

\subsubsection{The intramolecular S1...Pd1 interaction}

The length of the interaction between the axial sulfur S1 and Pd1 shortens as the pressure increases, from 3.159(10) $\AA$ at ambient pressure to 2.752(17) $\AA$ at $76.8 \mathrm{kbar}$, an overall decrease of 0.41(2) $\AA$ (Table 3, Figure 3): between ambient pressure and $42.5 \mathrm{kbar}$ it decreases from 3.159(10) $\AA$ to 3.009(5) $\AA$, a change of 0.150(11) $\AA$; during the phase change between 42.5 and 46 kbar it decreases 
by $0.160(9) \AA$ from 3.009(5) $\AA$ to 2.849(7) $\AA$; finally, between 46 and 76.8 kbar it decreases from 2.849 (7) $\AA$ to 2.752(17) $\AA$, a change of 0.097(18) $\AA$. It is noteworthy that the change observed over the relatively narrow range of $42.5-46$ kbar comprises $39 \%$ of the total shortening and is in contrast to the behaviour of the other complexes studied (see Supplementary Data Appendix B, Figure B1). The changes in the S1Pd1 distance are considerably larger than the statistically insignificant variations in the equatorial Pd-S distances: Pd1-S4 decreases by only 0.029(11) $\AA$, from 2.250(2) $\AA$ to 2.221(10)

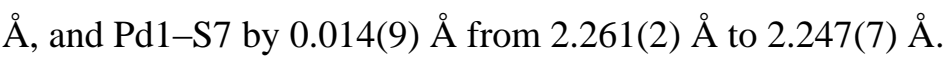

Between ambient pressure and $76.8 \mathrm{kbar}$ the $\mathrm{S} 1 \cdots \mathrm{Pd} 1-\mathrm{S} 4$ angle increases by $4.6(3)^{\circ}$, from $81.4(2)^{\circ}$ to $86.0(4)^{\circ}$, while the $\mathrm{S} 1 \cdots \mathrm{Pd} 1-\mathrm{S} 7$ angle increases by $5.7(5)^{\circ}$, from $78.2(3)$ to $83.9(4)^{\circ}$, indicating a more symmetric position for $\mathrm{S} 1$ above $\mathrm{Pd} 1$. These changes occur almost exclusively during the phase change (42.5-46 kbar, see Figure 4).

Table 3 Variation in the lengths of the $\mathrm{S} \cdots \mathrm{Pd}$ axial interactions in $\left[\mathrm{PdCl}_{2}\left([9] \mathrm{aneS}_{3}\right)\right]$ with pressure.

\begin{tabular}{|c|c|c|}
\hline Pressure/kbar & $\mathrm{S} 1 \cdots \mathrm{Pd} 1 / \AA$ & $\mathrm{Pd} 1 \cdots \mathrm{S} 4 \# 1 / \AA$ \\
\hline 0.001 & $3.159(10)$ & $3.525(8)$ \\
\hline 12.6 & $3.104(10)$ & $3.367(8)$ \\
\hline 23.5 & $3.058(9)$ & $3.323(7)$ \\
\hline 36.0 & $3.038(8)$ & $3.242(7)$ \\
\hline 42.5 & $3.009(5)$ & $3.204(5)$ \\
\hline 46.0 & $2.849(7)$ & $3.117(8)$ \\
\hline 53.5 & $2.815(18)$ & $3.088(16)$ \\
\hline 73.1 & $2.780(12)$ & $3.024(10)$ \\
\hline 76.8 & $2.752(17)$ & $3.006(10)$ \\
\hline
\end{tabular}

Symmetry code \#1: $x+1 / 2,-y+1 / 2,1-z$

\subsubsection{Effect on the $\mathrm{S}_{2} \mathrm{Cl}_{2} \mathrm{Pd}$ equatorial plane}

As with the $\mathrm{Pd}-\mathrm{S}$ distances described above, the $\mathrm{Pd}-\mathrm{Cl}$ distances are not significantly affected by increasing pressure: over the pressure range $0-76.8 \mathrm{kbar}, \mathrm{Pd} 1-\mathrm{Cl} 1$ decreases by only $0.023(14) \AA$ and Pd1-Cl2 by only $0.038(11) \AA$. During the phase change Cl1 appears to be displaced from the leastsquares mean plane defined by S4, S7 and Cl2 by 0.59(2) A. However, this displacement occurs in a direction approximately parallel to the $c$-axis direction, coinciding with the region in the diffraction pattern which is most shaded by the DAC; consequently we do not regard this displacement as a reliable feature of the evolving molecular geometry. This apparent displacement of $\mathrm{Cl} 1$ led us to define $\mathrm{S} 4 / \mathrm{S} 7 / \mathrm{Cl} 2$ as the reference coordination plane in preference to $\mathrm{S} 4 / \mathrm{S} 7 / \mathrm{Cl1} / \mathrm{Cl} 2$. The resulting displacement of $\operatorname{Pd} 1$ [0.080(5) $\AA$ at ambient pressure] shows no significant change up to $42.5 \mathrm{kbar}$, but decreases sharply by $0.091(7) \AA$ [from $0.096(3) \AA$ to $0.005(7) \AA$ ] between that pressure and 46 kbar, remaining in the $\mathrm{S} 4 / \mathrm{S} 7 / \mathrm{Cl} 2$ plane up to 76.8 kbar (Figure 5).

\subsubsection{Effect of pressure on the conformation of the macrocycle}


Although restraints were applied to the $\mathrm{S}-\mathrm{C}$ and $\mathrm{C}-\mathrm{C}$ distances for all six complexes, none were applied to the conformation of the macrocycle; the conformational features of the macrocycle can therefore be discussed. The phase change at $44 \mathrm{kbar}$ is accompanied by a series of changes from the overall [234] conformation of the macrocycle observed at ambient pressure. The conformation of the C9-S1-C2-C3-S4-C5 section is essentially unchanged, but the S4-C5-C6-S7 section adopts a more eclipsed, sterically less favourable arrangement, as seen by the change in the S4-C5-C6-S7 torsion angle from $-37.9(14)$ to $18(3)^{\circ}$ (Figure 6): this torsion angle approaches zero as the pressure is increased from $46 \mathrm{kbar}$ to $76.8 \mathrm{kbar}$. The apical sulfur atom moves to a more symmetrical position above the metal, and the S7-C8-C9-S1 arm adopts a visibly different conformation. The conformational changes in the [9] $\mathrm{aneS}_{3}$ ligand are clearly visible in Figure 7. At $46 \mathrm{kbar}$ the Dale notation (Dale, 1973) for the conformation of the macrocycle is close to [333] based on corners at C3, C6 and C9, but a less strict definition allowing pseudo-Dale corners gives the descriptor [1233], which better reflects the asymmetry in the macrocyclic conformation; further increases in pressure lead to even less symmetry within the macrocyclic ring.

\subsubsection{Effect on intermolecular $\mathrm{Pd}$ 'S interaction}

The potential of the title compounds for polymerisation via chain formation has been recognised by us and others (e.g., Grant et al., 2001). An intermolecular interaction between the metal atom Pd1 in the reference molecule and an equatorially-coordinated sulfur atom S4\#1 (symmetry code $\# 1: x+1 / 2,-y+1 / 2$, $1-z$, indicating the operation of the $2_{1}$ screw axis parallel to the $a$ axis) completes the distorted [4 +2$]$ octahedral coordination around Pd1 and links the molecules into polymeric chains. The length of this interaction decreases markedly with pressure, from 3.525(8) $\AA$ at ambient pressure to 3.022(14) $\AA$ at 76.8 kbar, a change of $0.503(16) \AA$. Most of the compression [0.321(9) $\AA$ ] occurs between ambient pressure and $42.5 \mathrm{kbar}$; the decrease across the phase change and between 46 and 76.8 kbar are only 0.088(9) $\AA$ and 0.094(16) $\AA$, respectively (Table 4, Figure 8). This behaviour is unique in the family of complexes studied (see Supplementary Data Appendix B, Figure B2).

We employed the van der Waals radii for Pd and S [1.63 and $1.80 \AA$, respectively, giving $\Sigma_{\mathrm{vdw}}=3.43$ $\AA$ (Bondi, 1964)] as a criterion of whether there was a real interaction between Pd1 and S4\#1 and if so the pressure at which this occurs: an interaction is deemed to be present if the Pd1..S4\#1 distance is within $\Sigma_{\mathrm{vdw}}$. At ambient pressure the distance is 3.525(8) $\AA$, so we conclude that no interaction is present, but by 12.6 kbar this distance has decreased to 3.367(8) $\AA$ and at this point we judge the

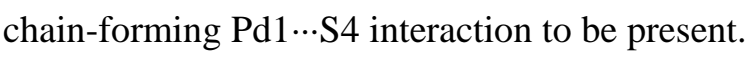

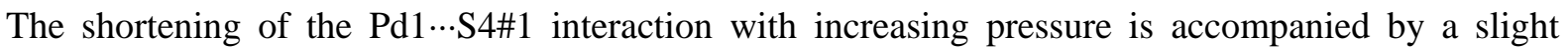
rotation of the reference and adjacent molecules relative to each other, which has the effect of aligning S4\#1 and Pd1 and reducing steric clashes as the molecules approach each other. The rotation is linked 


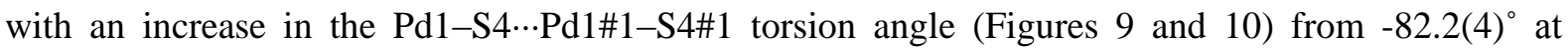
ambient pressure to $-86.1(4)^{\circ}$ at $42.5 \mathrm{kbar}$. During the phase change at 44 kbar the compression of the $\mathrm{Pd} 1 \cdots \mathrm{S} 4 \# 1$ distance is accompanied by a more rapid change in this torsion angle to $-92.9(4)^{\circ}$ at 46 kbar, but subsequent increases in pressure have little effect on the angle.

The contraction in the length of the Pd1 $\cdots \mathrm{S} 4 \# 1$ interaction at a pressure of $12.6 \mathrm{kbar}$ is also judged to indicate the onset of the change from the square planar coordination for Pd1 seen at ambient pressure to a distorted octahedral coordination. Many of the valence angles around Pd1 show little variation with pressure (see Supplementary Data), but several exhibit marked changes across the phase transition at 44 bar (Figure 11), tending towards values which are closer to the ideal octahedral angles of 90 or $180^{\circ}$. Thus there is a consistent trend towards the adoption of a more symmetric coordination sphere with increasing compression.

\subsection{Effects of pressure on the molecular geometry of $\left[\mathrm{PtCl}_{2}([9] \mathrm{aneS})\right]$}

\subsubsection{The structure of $\left[\mathrm{PtCl}_{2}\left([9] a n e S_{3}\right)\right]$ at ambient pressure}

The complex cis- $\left[\mathrm{PtCl}_{2}\left([9] \mathrm{aneS} \mathrm{S}_{3}\right)\right]$ crystallises in the chiral orthorhombic space group $P 2_{1} 2_{1} 2_{1}$ with $a$ $=7.564(2), b=12.223(4), c=12.248(2) \AA$ and $V=1132.1(5) \AA^{3}$ (Grant et al., 2001; Figure 12). The structure is isomorphous and isostructural with the $\mathrm{Pd}(\mathrm{II})$ analogue $\left[\mathrm{PdCl}_{2}\left([9] \mathrm{aneS}_{3}\right)\right]$ described above. The $\mathrm{Pt}(\mathrm{II})$ centre $(\mathrm{Pt} 1)$ in $\left[\mathrm{PtCl}_{2}\left([9] \mathrm{aneS}_{3}\right)\right]$ is surrounded by a distorted square planar array of two ciscoordinating sulfur atoms (S4 and S7) at 2.221(3) and 2.237(3) $\AA$, respectively, and two chloride ions (Cl1 and Cl2) at 2.336(4) and 2.321(3) $\AA$, respectively. The apical sulfur atom (S1) is endo with respect to the metal centre and participates in a long Pt1..S1 interaction of 3.260(3) $\AA$, which is within $\Sigma_{\mathrm{vdw}}$ for Pt and S (3.52 $\AA$; Bondi, 1964): the resulting coordination around Pd1 is described as $[4+1]$, with equatorially-bound donors S4, S7, Cl1 and Cl2 defining the base and S1 at the elongated apex. Pt1 is displaced from the plane of the two sulfur and two chloride donors by $0.0762(8) \AA$ in the direction of $\mathrm{S} 1$. The [9] $\mathrm{aneS}_{3}$ macrocycle is endodentate with respect to Pt1 and adopts a [234] conformation, with the Dale corners (Dale, 1973) occurring at C3, C5 and C8. The apical sulfur atom S1 does not occupy a position which is symmetrically above the metal centre and relative to the two

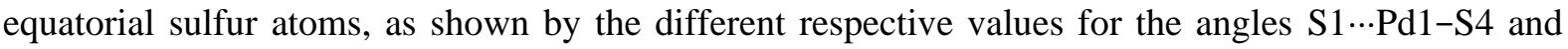

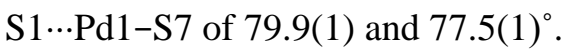

\subsubsection{Overview of the high pressure study of $\left[\mathrm{PtCl}_{2}\left([9] \mathrm{aneS} \mathrm{S}_{3}\right)\right]$}

Despite multiple attempts with different crystals, no viable dataset could be collected for $\left[\mathrm{PtCl}_{2}\left([9] \mathrm{aneS}_{3}\right)\right]$ at any pressure above $54 \mathrm{kbar}$. There is no distinct phase change such as that observed for $\left[\mathrm{PdCl}_{2}\left([9] \mathrm{aneS}_{3}\right)\right]$, nor are any discontinuous changes observed in the conformation of the macrocycle or the colour of the crystal. The significant changes which occur upon compression 
are therefore those associated with the distance between the apical sulfur atom and the Pt(II) metal centre and the length of the chain-forming interaction between each $\mathrm{Pt}(\mathrm{II})$ centre and an $\mathrm{S}$ atom in an adjacent molecule.

\subsubsection{Effect on the intramolecular S...Pt interaction}

The length of the interaction between the axial sulfur S1 and the Pt1 metal centre shortens smoothly and linearly as the pressure increases, from 3.264(2) $\AA$ at ambient pressure to 3.073(3) $\AA$ at $54 \mathrm{kbar}$ (Table 4, Figure S1). This decrease of 0.191(4) $\AA$ is much larger than those observed in the equatorial distances (see section 3.3.4).

Table 4 Variation in the lengths of the $\mathrm{S} \cdots \mathrm{Pt}$ interactions in $\left[\mathrm{PtCl}_{2}\left([9] \mathrm{aneS}_{3}\right)\right]$ with pressure.

\begin{tabular}{|l|l|l|}
\hline Pressure/kbar & S1 $\cdots \mathrm{Pt} 1 / \AA$ & $\mathrm{Pt} 1 \cdots \mathrm{S} 4 \# 1 / \AA$ \\
\hline 0.001 & $3.264(2)$ & $3.593(2)$ \\
\hline 3.0 & $3.264(3)$ & $3.569(4)$ \\
\hline 16.3 & $3.190(5)$ & $3.397(7)$ \\
\hline 16.4 & $3.211(3)$ & $3.424(4)$ \\
\hline 21.8 & $3.184(4)$ & $3.389(5)$ \\
\hline 28.8 & $3.154(7)$ & $3.326(10$ \\
\hline 32.7 & $3.139(4)$ & $3.298(6)$ \\
\hline 37.8 & $3.121(7)$ & $3.273(10)$ \\
\hline 41.9 & $3.102(4)$ & $3.258(6)$ \\
\hline 47.1 & $3.087(5)$ & $3.262(7)$ \\
\hline 54.0 & $3.073(3)$ & $3.244(5)$ \\
\hline
\end{tabular}

Symmetry code $\# 1: x+1 / 2,-y+1 / 2,1-z$

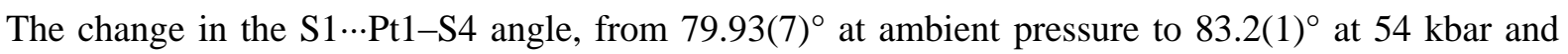
the $\mathrm{S} 1 \cdots \mathrm{Pt} 1-\mathrm{S} 7$ angle which changes from $77.36(7)^{\circ}$ at ambient pressure to $80.1(14)^{\circ}$, shows that as the axial S1‥Pt1 distance decreases with pressure S1 moves to a position which is more

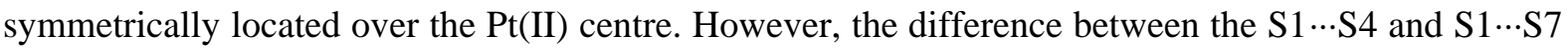
distances remains constant at around $0.100 \AA$ throughout, indicating that there is no lateral movement of $\mathrm{S} 1$.

\subsubsection{Effect on the $\mathrm{S}_{2} \mathrm{Cl}_{2} \mathrm{Pt}$ equatorial plane}

Increasing pressure from ambient to $54 \mathrm{kbar}$ has no significant effect on the $\mathrm{Pt}-\mathrm{Cl}$ distances: $\mathrm{Pt} 1-\mathrm{Cl} 1$ decreases by $0.026(10) \AA$, Pt1-Cl2 by $0.017(9) \AA$, while the Cl1-Pt1-Cl2 angle increases by $3.4(12)^{\circ}$. The Pt-S distances show small decreases: Pt1-S4 by 0.028(6) $\AA$ [from 2.221(2) $\AA$ to 2.193(6) $\mathrm{A}$ ] and Pt1-S7 by $0.049(7) \AA$ [from 2.240(2) $\AA$ to 2.191(7) $\AA$ ]. The displacement of Pt1 from the leastsquares mean plane through S4, S7, Cl1 and Cl2 increases by $0.025(3) \AA$, from $0.0713(15) \AA$ at ambient pressure to 0.096(2) $\AA$ at 54 kbar.

\subsubsection{Effect on the conformation of the macrocycle}


The conformation of the macrocycle in $\left[\mathrm{PtCl}_{2}\left([9] \mathrm{aneS}_{3}\right)\right]$ does not change under compression. Although the values of individual torsion angles fluctuate slightly (Figure S2), the standard uncertainties are such that these changes cannot be regarded as significant. This retention of the [234] conformation is in clear contrast to the flattening of the S4-C5-C6-S7 section of the macrocycle observed in $\left[\mathrm{PdCl}_{2}\left([9] \mathrm{aneS}_{3}\right.\right.$ (see section 3.2.5 above).

\subsubsection{Effect on the intermolecular S...Pt interaction}

The distance between Pt1 and the equatorial sulfur atom S4\#1 in a neighbouring molecule related by the $2_{1}$ screw axis parallel to the $a$ axis (symmetry code \#1: $x+1 / 2,-y+1 / 2,1-z$ ) decreases with pressure,

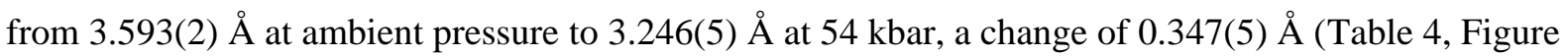
S3). Mirroring the trends in the unit cell dimensions, over half of this compression [0.195(8) $\AA$ ]

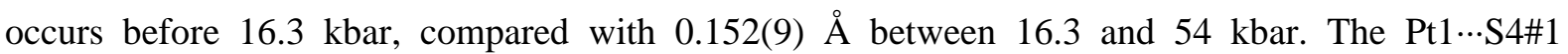
distance at ambient pressure slightly exceeds $\Sigma_{\mathrm{vdw}}$ for Pt and S (3.52 ̊̊; Bondi, 1964), but by ca. 7 kbar (Table 4, Figure S3, by interpolation) it has decreased to below this limit, at which point we determine that the chain-forming Pt $1 \cdots \mathrm{S} 4 \# 1$ interaction is present. This decrease in distance confers a distorted octahedral $[4+2]$ coordination on the metal centre, but in contrast to $\left[\operatorname{PdCl}_{2}\left([9] \mathrm{aneS} \mathrm{S}_{3}\right)\right]$ the valence angles around the metal are essentially invariant with pressure.

\subsection{Effects of pressure on the molecular geometry of $\left[\mathrm{PdBr}_{2}\left([9] a n e S_{3}\right)\right]$}

\subsubsection{The structure of $\left.\left[\mathrm{PdBr}_{2}([9]]_{a n e} S_{3}\right)\right]$ at ambient pressure}

The complex cis- $\left[\operatorname{PdBr}_{2}\left([9] \mathrm{aneS}_{3}\right)\right]$ crystallises in the orthorhombic space group $P 2_{1} 2_{1} 2_{1}$ with $a=$ 7.578(1), $b=12.281(3), c=12.594(2) \AA$ and $V=1171.1(6) \AA^{3}$ (Figure 13; Wieghardt et al., 1986). It is isostructural and isomorphous with the dichloro analogues $\left[\mathrm{PdCl}_{2}\left([9] \mathrm{aneS}_{3}\right)\right]$ and $\left[\mathrm{PtCl}_{2}\left([9] \mathrm{aneS}_{3}\right)\right]$ described above. The Pd(II) centre Pd1 is coordinated by two cis-coordinating sulfur atoms (S4 and S7) at 2.257(2) and 2.275(2) $\AA$, respectively, and two bromide ions ( $\mathrm{Br} 1$ and $\mathrm{Br} 2)$ at 2.456(1) and 2.468(1) $\AA$, respectively, forming a distorted square planar arrangement. This coordination is supplemented by a long interaction from the apical, endodentate sulfur donor S1 located 3.125(1) $\AA$ from the metal. The length of this apical $\mathrm{Pd} \cdots \mathrm{S}$ interaction is shorter than the corresponding distance of 3.159(10) $\AA$ in $\left[\mathrm{PdCl}_{2}\left([9] \mathrm{aneS}_{3}\right)\right]$, consistent with bromide being a poorer $\pi$-donor than chloride. The coordination of Pd1 at ambient pressure can therefore be described as $[4+1]$, with the base defined by the equatorial donors $\mathrm{S} 4, \mathrm{~S} 7, \mathrm{Br} 1$ and $\mathrm{Br} 2$, and $\mathrm{S} 1$ at the apex. The metal centre sits above the plane defined by four donor atoms, by $0.0957(10) \AA$ in the direction of S1. The [9]aneS $S_{3}$ macrocycle adopts the same [234] conformation as in $\left[\mathrm{PdCl}_{2}\left([9] \mathrm{aneS}_{3}\right)\right]$ and $\left[\mathrm{PtCl}_{2}\left([9] \mathrm{aneS}_{3}\right)\right]$ : the Dale corners (Dale, 1973) which define the conformation again occur at C3, C5 and C8. 


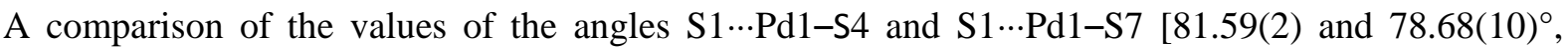
respectively] shows them to differ by $2.91(10)^{\circ}$, indicating that $\mathrm{S} 1$ does not occupy a symmetrical position between and above the two equatorial sulfur atoms; correspondingly, the distances between the axial sulfur atom S1 and the equatorial sulfur atoms S4 and S7 are 3.579(4) and 3.481(5) $\AA$, placing S1 closer to S7 than to S4 by 0.098(6) A.

\subsubsection{Overview of the high pressure study of $\left[\operatorname{PdBr}_{2}\left([9] a n e S_{3}\right)\right]$}

As with $\left[\mathrm{PtCl}_{2}\left([9] \mathrm{aneS}_{3}\right)\right]$, there is neither the distinct phase as observed for $\left[\mathrm{PdCl}_{2}\left([9] \mathrm{aneS}_{3}\right)\right]$ nor any discontinuous changes in the conformation of the macrocycle or the colour of the crystal. The significant changes upon compression involve the apical S...Pd distance and the intermolecular chainforming $S \cdots P d$ interaction.

\subsubsection{Effect on the intramolecular S...Pd interaction}

The distance between the axial sulfur S1 and Pd1 shortens as the pressure increases, from 3.126(2) $\AA$ at ambient pressure to 2.858(5) $\AA$ at 116.9 kbar (Table 5, Figure S4), a decrease of 0.268(5) $\AA$. This is a much larger change than those seen in the equatorial distances Pd1-S4 [which decreases from

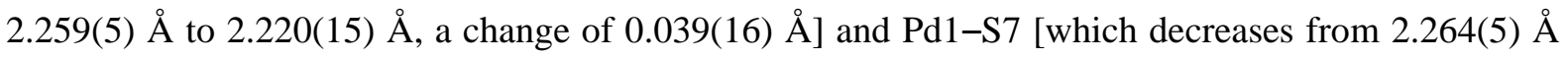
to 2.236(19) $\AA$ a change of $0.028(2) \AA$ ] Even with the overall contraction of $0.268(5) \AA$, at $116 \mathrm{kbar}$ the $\mathrm{Pd} 1 \cdots \mathrm{S} 1$ distance remains considerably longer than the equatorial $\mathrm{Pd}-\mathrm{S}$ distances. Over the pressure range from ambient to $116.9 \mathrm{kbar}$, the $\mathrm{S} 1 \cdots \mathrm{Pd} 1-\mathrm{S} 4$ angle increases from $81.6(2)^{\circ}$ to $85.6(1)^{\circ}$,

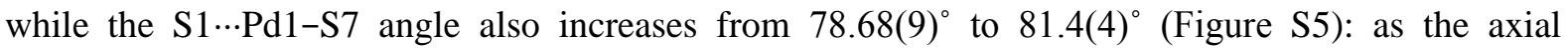
Pd1 $\cdots$ S1 distance decreases, S1 becomes more symmetrically located above Pd1.

Table 5 Variation in the lengths of the $\mathrm{S} 1 \cdots \mathrm{Pd} 1$ interactions in $\left[\mathrm{PdBr}_{2}\left([9] \mathrm{aneS}_{3}\right)\right]$ with pressure.

\begin{tabular}{|l|l|l|}
\hline Pressure/kbar & $\mathrm{S} 1 \cdots \mathrm{Pd} 1 / \AA$ & $\mathrm{Pd} 1 \cdots \mathrm{S} 4 \# 1 / \AA$ \\
\hline 0.001 & $3.126(2)$ & $3.549(3)$ \\
\hline 4.6 & $3.1224(16)$ & $3.536(3)$ \\
\hline 25.0 & $3.0454(14)$ & $3.324(3)$ \\
\hline 30.4 & $3.051(4)$ & $3.324(6)$ \\
\hline 40.1 & $3.003(3)$ & $3.255(6)$ \\
\hline 50.0 & $2.980(4)$ & $3.204(7)$ \\
\hline 64.7 & $2.962(4)$ & $3.182(7)$ \\
\hline 71.3 & $2.900(5)$ & $3.124(10)$ \\
\hline 81.9 & $2.898(4)$ & $3.107(7)$ \\
\hline 96.5 & $2.859(4)$ & $3.070(7)$ \\
\hline 102.6 & $2.869(3)$ & $3.073(5)$ \\
\hline 116.9 & $2.858(5)$ & $3.058(9)$ \\
\hline
\end{tabular}

Symmetry code \#1: $x+1 / 2,-y+1 / 2,1-z$

\subsubsection{Effect on the $\mathrm{S}_{2} \mathrm{Br}_{2} \mathrm{Pd}$ equatorial plane}


Although the lengths of the $\mathrm{Pd}-\mathrm{Br}$ bonds are unaffected by compression, they do move further apart, as shown by the increase of $3.3(4)^{\circ}$ in the $\mathrm{Br} 1-\mathrm{Pd} 1-\mathrm{Br} 2$ angle, from $93.5(2)^{\circ}$ at ambient pressure to $96.8(4)^{\circ}$ at 116.4 kbar: corresponding decreases are observed in the $\mathrm{S}-\mathrm{Pd}-\mathrm{Br}$ angles (Figure S6). The displacement of Pd1 from the co-ordination plane formed by $\mathrm{Br} 1, \mathrm{Br} 2, \mathrm{~S} 4$ and S7 increases smoothly by $0.046(3) \AA ̊$ over the pressure range studied, from $0.0957(10) \AA$ at ambient pressure to $0.142(3) \AA$ at $116.9 \mathrm{kbar}$.

\subsubsection{Effect on the conformation of the macrocycle}

The conformation of the macrocycle remains unchanged across the pressure range studied, as indicated by the values of the torsion angles and their associated standard uncertainties (see Figure S7). The [234] conformation of the macrocycle is, therefore, retained throughout.

\subsubsection{Effect on the intermolecular S...Pd interaction}

There is potential for an additional, long-range $\mathrm{Pd}^{\cdots} \mathrm{S}$ interaction between the metal centre and an equatorially-coordinated S4 donor atom in a neighbouring molecule related by the operation of a 21 screw axis parallel to the $a$ axis of the unit cell. At ambient pressure the distance between the relevant

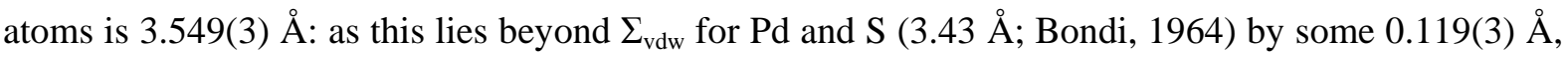
no interaction is deemed to exist. However, the distance decreases smoothly with increasing pressure

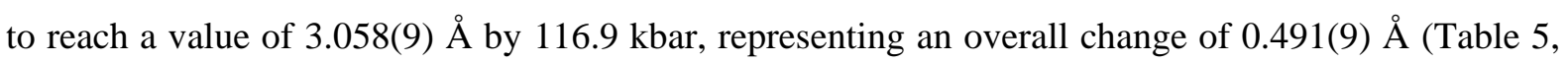
Figure S8); by $c a$. $15 \mathrm{kbar}$ it had fallen below $\Sigma_{\mathrm{vdw}}$, at which point we consider the chain-forming $\operatorname{Pd} 1 \cdots \mathrm{S} 4$ interaction to be present and a distorted octahedral [4 +2$]$ coordination conferred on the metal centre. As with $\left[\mathrm{PtCl}_{2}\left([9] \mathrm{aneS}_{3}\right)\right]$, the valence angles around the metal in $\left[\operatorname{PdBr}_{2}\left([9] \mathrm{aneS}_{3}\right)\right]$ appear essentially invariant with pressure. The $\mathrm{Pd}-\mathrm{S}$ and $\mathrm{Pd}-\mathrm{Br}$ distances are marginally but systematically shorter at 116.9 kbar than at ambient pressure.

\subsection{Effects of pressure on the molecular geometry of $\left[\mathrm{PtBr}_{2}\left([9] a n e S_{3}\right)\right]$}

\subsubsection{The structure of $\left[\mathrm{PtBr}_{2}\left([9] a n e S_{3}\right)\right]$ at ambient pressure}

The complex cis-[ $\left.\operatorname{PtBr}_{2}\left([9] \mathrm{aneS}_{3}\right)\right]$ crystallises in the orthorhombic space group $P 2{ }_{1} 2_{1} 2_{1}$ with $a=$ 7.4940(12), $b=12.143(2), c=12.93(4) \AA$ and $V=1177(4) \AA^{3}$. The Pt(II) centre occupies a distorted square planar coordination environment comprising two cis-coordinating sulfur atoms S4 and S7 at 2.263(6) and 2.241(6) $\AA$, respectively, and two bromide ions Br1 and Br2 at 2.480(4) and 2.467(4) respectively (Figure 14). A long S...Pt interaction from the endodentate apical sulfur S1 at 3.2054(17)

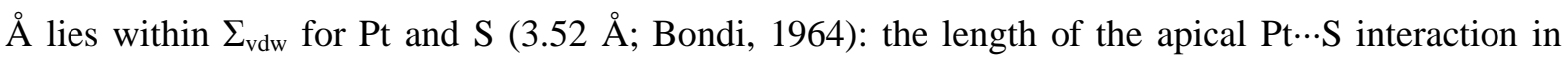
$\left[\operatorname{PtBr}_{2}\left([9] \mathrm{aneS}_{3}\right)\right]$ is noticeably shorter than the corresponding distance of $3.264(2) \AA$ in 
$\left[\mathrm{PtCl}_{2}\left([9] \mathrm{aneS}_{3}\right)\right]$. The metal centre sits above the least-squares mean plane defined by these four donor atoms, by $0.0739(10) \AA$ in the direction of S1.

The [9] $\mathrm{aneS}_{3}$ macrocycle is endodentate to the $\mathrm{Pt}(\mathrm{II})$ centre and adopts a [234] conformation, with Dale corners (Dale, 1973) located at the atoms C3, C5 and C8. A comparison of the angles S1 $\cdots$ Pt1-

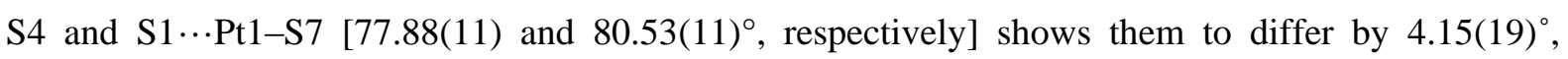
indicating that the position of $\mathrm{S} 1$ is not symmetrical with respect to the two equatorial sulfur atoms.

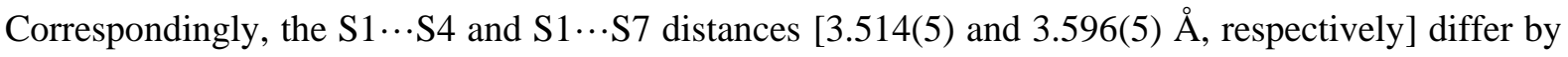
0.083(7) A, placing S1 slightly closer to S4 than to S7. The coordination at the metal centre can be best described as $[4+1]$ with $\mathrm{S} 4, \mathrm{~S} 7, \mathrm{Br} 1$ and $\mathrm{Br} 2$ defining a basal plane and $\mathrm{S} 1$ the more remote apex. As for other members of this family, molecules of $\left[\mathrm{PtBr}_{2}\left([9] \mathrm{aneS}_{3}\right)\right]$ are pre-organised for a long range $\mathrm{S} 1 \cdots \mathrm{Pt}$ interaction between $\mathrm{Pt} 1$ in the reference molecule and the equatorial S-donor S7 in a neighbouring molecule related by the operation of a screw axis parallel to the $a$ axis of the unit cell (Figure S9). At ambient pressure the distance between these two atoms is 3.573(3) $\AA$, slightly [0.053(3) ̊] outside $\Sigma_{\mathrm{vdw}}$ for Pt and S (3.52 ̊; Bondi, 1964), so no interaction is yet deemed to exist.

\subsubsection{Overview of the high pressure study of $\left[\operatorname{PtBr}_{2}\left([9] a n e S_{3}\right)\right]$}

As with $\left[\operatorname{PtCl}_{2}\left([9] \mathrm{aneS}_{3}\right)\right]$ and $\left[\operatorname{PdBr}_{2}\left([9] \mathrm{aneS}_{3}\right)\right],\left[\operatorname{PtBr}_{2}\left([9] \mathrm{aneS}_{3}\right)\right]$ compression does not induce a distinct phase change as seen for $\left[\mathrm{PdCl}_{2}\left([9] \mathrm{aneS}_{3}\right)\right]$. The crystal undergoes no discontinuous changes, for example in the conformation of the macrocycle or the colour of the crystal. The significant changes which occur involve the lengths of the apical S $\cdots P t$ interaction and the chain-forming S $\cdots P t$ interaction between the metal centre in the reference molecule and an $\mathrm{S}$ atom in an adjacent molecule.

\subsubsection{Effect on the intramolecular S ...Pt interaction}

The interaction between the axial sulfur S1 and Pt1 shortens as the pressure increases, from

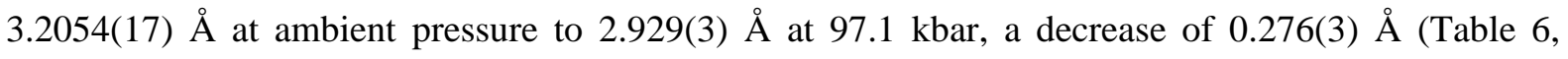
Figure S10). In contrast, the changes in the equatorial Pt-S distances are statistically insignificant: Pt1-S4 decreases by $0.018(11) \AA$, from 2.263(6) $\AA$ to 2.245(9) $\AA$, while Pt1-S7 decreases by

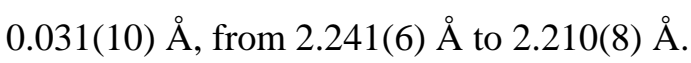

Table 6 Variation in the lengths of the S $\cdots \mathrm{Pt}$ interactions in $\left[\mathrm{PtBr}_{2}\left([9] \mathrm{aneS}_{3}\right)\right]$ with pressure.

\begin{tabular}{|l|l|l|}
\hline Pressure/kbar & $\mathrm{S} 1 \cdots \mathrm{Pt} 1 / \AA$ & $\mathrm{Pt} 1 \cdots \mathrm{S} 4 \# 1 / \AA$ \\
\hline 0.001 & $3.2054(17)$ & $3.575(3)$ \\
\hline 2.7 & $3.1947(19)$ & $3.539(4)$ \\
\hline 17.0 & $3.103(2)$ & $3.350(5)$ \\
\hline 32.7 & $3.071(3)$ & $3.291(6)$ \\
\hline 42.5 & $3.050(2)$ & $3.262(4)$ \\
\hline 48.2 & $3.040(3)$ & $3.231(6)$ \\
\hline 62.5 & $2.996(2)$ & $3.199(4)$ \\
\hline 74.9 & $2.958(3)$ & $3.162(5)$ \\
\hline
\end{tabular}




\begin{tabular}{|l|l|l|}
\hline 82.6 & $2.945(3)$ & $3.150(5)$ \\
\hline 88.8 & $2.933(3)$ & $3.140(5)$ \\
\hline 97.1 & $2.929(3)$ & $3.136(5)$ \\
\hline
\end{tabular}

Symmetry code \#1: $x+1 / 2,-y+1 / 2,1-z$

Between ambient pressure and $97.1 \mathrm{kbar}$ the $\mathrm{S} 1 \cdots \mathrm{Pt} 1-\mathrm{S} 4$ angle moves from $80.53(11)$ to $84.68(15)^{\circ}$,

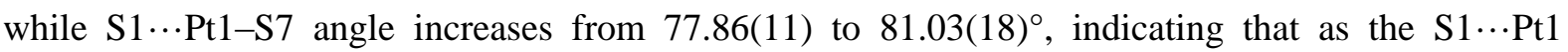
distance decreases S1 occupies a position which is more symmetrically located above the metal (Figure S11).

\subsubsection{Effects of pressure in the $\mathrm{S}_{2} \mathrm{Br}_{2} \mathrm{Pt}$ equatorial plane}

The Pt-Br distances do not alter significantly over the pressure range 0-97.1 kbar: the length of Pt1$\mathrm{Br} 1$ decreases by $0.020(5)$ and that of $\mathrm{Pt} 1-\mathrm{Br} 2$ by $0.011(5) \AA$. The separation of the two bromides increases with increased pressure, with the $\mathrm{Br} 1-\mathrm{Pt} 1-\mathrm{Br} 2$ angle increasing from $90.45(18)$ to $95.3(2)^{\circ}$, an increase of $4.9(3)^{\circ}$. However, this change does not affect the two bromides equally since the S7Pt1-Br1 angle decreases from $175.49(10)$ to $171.17(17)^{\circ}$ while the S4-Pt1-Br2 angle decreases only slightly from $176.74(7)$ to $175.82(11)^{\circ}$ (Figure S12).

As the pressure increases the $\mathrm{Pt}(\mathrm{II})$ centre moves further away from the equatorial plane defined by $\mathrm{Br} 1, \mathrm{Br} 2$, S4 and S7: the displacement increases from 0.0739(10) $\AA$ at ambient pressure to $0.0995(10)$ $\AA$ at 97.1 kbar. The positions of C5 and C6 also change differently in relation to this plane: C5 lies 0.46(9) $\AA$ below the plane at ambient pressure and moves to lie only 0.32(1) $\AA$ above the plane at 97.1 kbar, while C6 lies 0.01(1) $\AA$ above the plane at ambient pressure and moves to 0.20(2) $\AA$ above the plane at $97.1 \mathrm{kbar}$.

\subsubsection{Effects of pressure on the conformation of the macrocycle}

The conformation of the macrocycle, described as [234] in the Dale notation (Dale, 1973), remains unchanged upon the application of higher pressures. Individual torsion angles (see Figure S13) fluctuate slightly but within the standard uncertainties, in common with the situation observed for $\left[\mathrm{PtCl}_{2}\left([9] \mathrm{aneS}_{3}\right)\right]$ and $\left[\mathrm{PdBr}_{2}\left([9] \mathrm{aneS}_{3}\right)\right]$.

\subsubsection{Effects of pressure on the intermolecular S $\ldots$. Pt interaction}

The length of the intermolecular interaction between Pt1 and an equatorial sulfur atom S4\#1 in a neighbouring molecule related by the $2_{1}$ screw axis parallel to $a$ (symmetry code: $\# 1=x+1 / 2,-y+1 / 2,1$ z) decreases with pressure, from 3.575(3) $\AA$ at ambient pressure to 3.136(5) $\AA$ at 97.1 kbar (Table 6, Figure S14). Taking $\Sigma_{\mathrm{vdw}}$ for Pt and S as $3.52 \AA$ (Bondi, 1964), we observe that by $c a .5$ kbar the separation of the two atoms lies within this sum and a Pt...S interaction exists. Between ambient pressure and $97.1 \mathrm{kbar}$, the S4-Pt1 $\cdots \mathrm{S} 4 \# 1$ angle decreases slightly from 88.92(9) to 85.23(11) ${ }^{\circ}$. There is no systematic shortening of the $\mathrm{Pt}-\mathrm{S}$ or $\mathrm{Pt}-\mathrm{Br}$ distances across the pressure range studied. 


\subsection{Effects of pressure on the molecular geometry of $\left[\mathrm{Pdl}_{2}\left([9] \mathrm{ane} \mathrm{S}_{3}\right)\right]$}

\subsubsection{The structure of $\left[\mathrm{Pdl}_{2}\left([9] a n e S_{3}\right)\right]$ at ambient pressure}

The complex cis-[PdI $\left.\left([9] \mathrm{aneS}_{3}\right)\right]$ crystallises in the orthorhombic space group $P 2{ }_{1} 2_{1} 2_{1}$ with $a=$ 7.6317(4), $b=12.6036(7), c=13.0266(7) \AA$ and $V=1252.99(12) \AA^{3}$. The structure, which has not been reported previously, is isomorphous with those of $\left[\mathrm{PdCl}_{2}\left([9] \mathrm{aneS} \mathrm{S}_{3}\right)\right],\left[\mathrm{PtCl}_{2}\left([9] \mathrm{ane} \mathrm{S}_{3}\right)\right]$ and $\left[\operatorname{PdBr}_{2}\left([9] \mathrm{aneS}_{3}\right)\right]$ discussed above. The $\mathrm{Pd}(\mathrm{II})$ centre $\mathrm{Pd} 1$ occupies a distorted square planar environment consisting of two cis-coordinating sulfur atoms S4 and S7 at 2.276(3) and 2.287(3) respectively, and two iodides I1 and I2 at 2.6003(13) and 2.6197(12) $\AA$, respectively (Figure 15). The

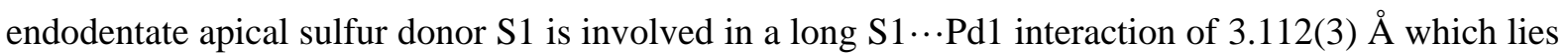
well within $\Sigma_{\mathrm{vdw}}$ for Pd and S (3.43 $\AA$; Bondi, 1964). Pd1 lies above the $\mathrm{S}_{2} \mathrm{I}_{2}$ plane by $0.0868(12) \AA$. The [9] ane $\mathrm{S}_{3}$ macrocycle is endodentate to $\mathrm{Pd} 1$ and adopts a [234] conformation, with Dale corners

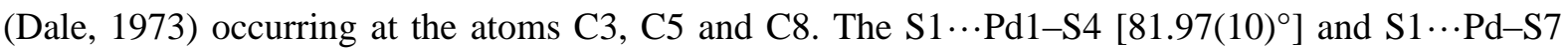
$\left[78.68(10)^{\circ}\right]$ angles are inequivalent and the difference of $3.29(14) \AA$ between them indicates that the position of $\mathrm{S} 1$ is asymmetric with respect to the two equatorial sulfur atoms. The corresponding distance between S1 and the equatorial sulfur atoms S4 and S7 are 3.592(3) and 3.484(4) $\AA$, respectively, placing S1 0.108(5) A closer to S7.

$\mathrm{Pd}(\mathrm{II})$ tends to adopt a square planar geometry, but in $\left[\mathrm{PdI}_{2}\left([9] \mathrm{aneS}_{3}\right)\right]$ its coordination is best described as [4+1] with S4, S7, I1 and I2 as the base and S1 defining the apex. There is potential for a long-range intermolecular interaction between the Pd1 and an equatorial sulfur S4 in a neighbouring molecule related by the $2_{1}$ screw axis parallel to the $a$ axis of the unit cell. At ambient pressure their separation of 3.596(3) $\AA$ lies 0.166(3) outside $\Sigma_{\text {vdw }}$ for Pd and S (3.43 $\AA$; Bondi, 1964), so no interaction is deemed to exist.

\subsubsection{Overview of the high pressure study of $\left[\mathrm{Pdl}_{2}\left([9] a n e S_{3}\right)\right]$}

The behaviour of $\left[\operatorname{PdI}_{2}\left([9] \mathrm{aneS}_{3}\right)\right]$ under compression is similar to that seen for $\left[\operatorname{PtCl}_{2}\left([9] \mathrm{aneS}_{3}\right)\right]$, $\left[\operatorname{PdBr}_{2}\left([9] \mathrm{aneS}_{3}\right)\right]$ and $\left[\mathrm{PtBr}_{2}\left([9] \mathrm{aneS}_{3}\right)\right]$ insofar as the discontinuous changes exhibited by $\left[\mathrm{PdCl}_{2}\left([9] \mathrm{aneS}_{3}\right)\right]$ are absent. The significant changes which occur involve the apical $\mathrm{S} \cdots \mathrm{Pd}$ interaction, the chain-forming S $\cdots \mathrm{Pd}$ interaction and $\mathrm{I} \cdots \mathrm{I}$ contacts which cross-link the chains into a two-dimensional extended structure.

\subsubsection{Effect of pressure on the intramolecular S $\cdots$ Pd interaction}

The interaction between the axial sulfur S1 and the metal centre shortens as the pressure increases,

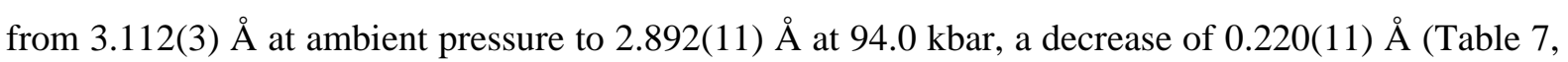
Figure S15). The corresponding equatorial $\mathrm{Pd}-\mathrm{S}$ distances are barely affected: S4-Pd1 decreases by 


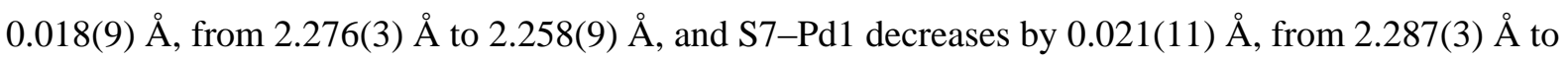
$2.266(11) \AA]$.

Table 7 Variation in the lengths of the interactions in $\left[\mathrm{PdI}_{2}\left([9] \mathrm{aneS} \mathrm{S}_{3}\right)\right]$ with pressure.

\begin{tabular}{|l|l|l|l|}
\hline Pressure/kbar & $\mathrm{S} 1 \cdots \mathrm{Pd} 1 / \AA$ & $\mathrm{Pd} 1 \cdots \mathrm{S} 4 \# 1 / \AA$ & $\mathrm{I} 1 \cdots \mathrm{I} 2 \# 2 / \AA$ \\
\hline 0.001 & $3.112(3)$ & $3.596(3)$ & $4.2447(12)$ \\
\hline 7.9 & $3.065(8)$ & $3.436(7)$ & $4.062(4)$ \\
\hline 19.0 & $3.055(8)$ & $3.359(7)$ & $3.983(4)$ \\
\hline 30.0 & $3.023(7)$ & $3.255(6)$ & $3.876(3)$ \\
\hline 36.6 & $2.991(5)$ & $3.224(5)$ & $3.836(2)$ \\
\hline 41.9 & $2.977(7)$ & $3.201(6)$ & $3.818(4)$ \\
\hline 57.7 & $2.936(7)$ & $3.122(7)$ & $3.724(3)$ \\
\hline 60.4 & $2.930(7)$ & $3.132(7)$ & $3.728(3)$ \\
\hline 66.0 & $2.951(7)$ & $3.124(6)$ & $3.728(3)$ \\
\hline 79.4 & $2.908(7)$ & $3.087(6)$ & $3.673(3)$ \\
\hline 94.0 & $2.892(11)$ & $3.034(10)$ & $3.632(4)$ \\
\hline
\end{tabular}

Symmetry code $\# 1: x+1 / 2,-y+1 / 2,1-z ; \# 2=2-x, y+1 / 2,-z+\frac{3}{2} / 2$

The $\mathrm{S} 1 \cdots \mathrm{Pd} 1-\mathrm{S} 4$ angle increases from $81.97(10)^{\circ}$ at ambient pressure to $85.5(3)^{\circ}$ at $94 \mathrm{kbar}$, as does the S1․PPd1-S7 angle, from 78.68(10) at ambient pressure to 79.8(3) at $94 \mathrm{kbar}$ (Figure S16). These values indicate the movement of $\mathrm{S} 1$ as the length of axial $\mathrm{S} 1 \cdots \mathrm{Pd} 1$ interaction decreases, but the atom remains in an asymmetric position above Pd1. A comparison of the S1 $\cdots \mathrm{S} 4$ and the $\mathrm{S} 1 \cdots \mathrm{S} 7$ distances show that the former reduces from 3.592(3) $\AA$ to 3.53(2) $\AA$, a compression of 0.06(2) $\AA$, while the

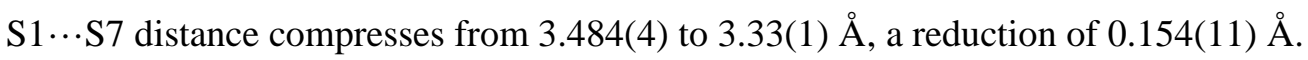

\subsubsection{Effects of pressure on the conformation of the macrocycle}

The conformation of the macrocycle is essentially unchanged with increased pressure (see Figure S17) and the conformational descriptor [234] is therefore maintained.

\subsubsection{Effects of pressure in the $S_{2} I_{2} P d$ equatorial plane}

The Pd1-I1 and Pd1-I2 distances both shorten slightly between ambient pressure and 94.0 kbar: the length of the Pd1-I1 bond contracts from 2.6003(13) to 2.564(4) $\AA$, a change of 0.036(4) $\AA$, while Pd1-I2 reduces from 2.6197(12) to 2.596(4) A, a change of 0.024(4) $\AA$. The I1-Pd1-I2 angle does not change significantly. The displacement of Pd1 from the equatorial plane (defined by I1, I2, S4 and S7)

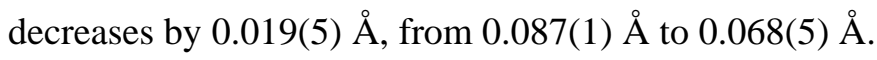

\subsubsection{Effect of pressure on the intermolecular S...Pd interaction}

The length of the intermolecular interaction between the Pd1 and an equatorial sulfur atom S4\#1 in a neighbouring molecule related by the $2_{1}$ screw axis parallel to $a$ (symmetry code $\# 1$ : $x+1 / 2,-y+1 / 2,1-z$ ) decreases from 3.596(3) $\AA$ at ambient pressure to 3.034(10) $\mathrm{A}$ at 94 kbar, a change of 0.562(10) $\AA$ (Table 7, Figure S18). The value of $\Sigma_{\mathrm{vdw}}$ for Pd and S is $3.43 \AA$ (Bondi, 1964), and the shortening of 
the Pd1 $\cdots$ S4\#1 distance falls below this limit at a pressure of about $7.9 \mathrm{kbar}$, at which point the interaction is deemed to exist and that chain formation has occurred, resulting in distorted octahedral coordination at Pd1.

\subsubsection{Effects of pressure on iodide...iodide catenation}

Each iodide ligand can potentially interact with iodides in two neighbouring molecules to give a total

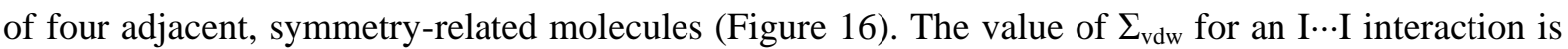
$3.96 \AA$ Á (Bondi, 1964), and at ambient pressure neither the shorter [4.2447(12) Á] nor the longer [5.013(2) Á] interaction lies within this limit. At ambient pressure the difference between the shorter and longer distances is $0.768(2) \AA$; as the pressure increases to 94.0 kbar very similar decreases in the two distances are observed, the shorter contracting by 0.613(4) $\AA$ and the longer by 0.597(3) $\AA$, reductions of $14.4 \%$ and $11.8 \%$, respectively (Figure S19). By ca. 20 kbar the shorter distance has

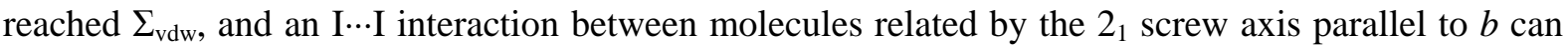
be said to exist; this distance continues to contract, and at $94.0 \mathrm{kbar}$ is $0.328(4) \AA$ shorter than $\Sigma_{\mathrm{vdw}}$. In contrast, its initial greater length and somewhat smaller degree of contraction of the longer distance with increasing pressure means that it never approaches $\Sigma_{\mathrm{vdw}}$, even at $94.0 \mathrm{kbar}$ : at this point its length of 4.416(3) $\AA$ lies 0.456(3) $\AA$ outside the van der Waals limit. The combination of the chain-forming $\operatorname{Pd} 1 \cdots \mathrm{S} 4(x+1 / 2,-y+1 / 2, z-1)$ and $\mathrm{I} 1 \cdots \mathrm{I} 2\left(2-x, y+1 / 2,-z+\frac{3}{2}\right)$ interactions (Figure 17) generates a twodimensional sheet of molecules in the (110) plane. The dimensionality of $\left[\operatorname{PdI}_{2}\left([9] \mathrm{aneS}_{3}\right)\right]$ is, therefore, different from that of the four previous complexes.

\subsection{Effects of pressure on the molecular geometry of $\left[\mathrm{Ptl}_{2}\left([9] a n e S_{3}\right)\right]$}

\subsubsection{The ambient pressure structure}

The complex cis-[ $\left.\operatorname{PtI}_{2}\left([9] \mathrm{aneS}_{3}\right)\right]$ crystallises in the orthorhombic space group $P 2{ }_{1} 2_{1} 2_{1}$ with $a=$ 7.6565(11), $b=12.5183(2), c=13.0459(4) \AA$ and $V=1250.4(1) \AA^{3}$ (Figure 18; Grant et al., 2001). The Pt(II) centre is surrounded by a distorted square planar arrangement of two cis-coordinating sulfur donors (S4 and S7) at 2.253(2) and 2.268(2) ^, respectively, and two iodides (I1 and I2) at

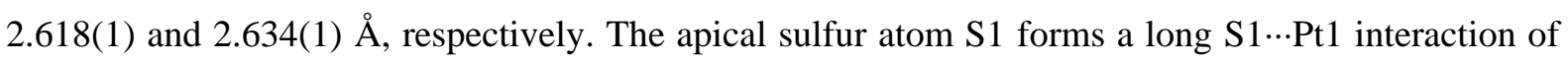
3.207(2) $\AA$, and the metal is displaced from the plane of the four donor atoms, by 0.079(6) $\AA$ in the direction of S1. The [9] $\mathrm{aneS}_{3}$ macrocycle is endodentate to the Pt1 and, allowing a less strict definition of a Dale corner (Dale, 1973), can be said to adopt a typical [234] conformation. The respective values of the $\mathrm{S} 1^{\cdots} \mathrm{Pt} 1-\mathrm{S} 4$ and $\mathrm{S} 1^{\cdots \cdots} \mathrm{Pt} 1-\mathrm{S} 7$ angles [81.23(7) and 78.02(7) ${ }^{\circ}$ ] show them differing by $3.21(10)^{\circ}$ and establishes that $\mathrm{S} 1$ is not symmetrically placed between and above the two equatorial sulfur atoms. The geometry at Pt1 is essentially square planar with S4, S7, I1 and I2 defining the equatorial plane, and the long interaction to $\mathrm{S} 1$ at the apex completing the $[4+1]$ 
coordination. A potential long-range intermolecular interaction is detectable, involving Pt1 in the reference molecule and a equatorial S4 in a neighbouring molecule along the $a$ axis, but at ambient pressure these atoms are well separated at a distance of 3.659(2) A.

\subsubsection{Overview of the high pressure study of $\left[\operatorname{Ptl}_{2}\left([9] a n e S_{3}\right)\right]$}

The behaviour of $\left[\operatorname{PtI}_{2}\left([9] \mathrm{aneS}_{3}\right)\right]$ is similar to that of $\left[\operatorname{PtCl}_{2}\left([9] \mathrm{aneS}_{3}\right)\right], \quad\left[\operatorname{PdBr}_{2}\left([9] \mathrm{aneS}_{3}\right)\right]$, $\left[\operatorname{PtBr}_{2}\left([9] \mathrm{aneS}_{3}\right)\right]$ and $\left[\mathrm{PdI}_{2}\left([9] \mathrm{aneS}_{3}\right)\right]$ insofar as compression dos not induce the range of discontinuous changes seen for $\left[\mathrm{PdCl}_{2}\left([9] \mathrm{aneS}_{3}\right)\right]$. The significant changes which occur involve the apical S $\cdots P$ Pt interaction, the chain-forming S $\cdots P t$ interaction and I $\cdots$ I contacts which cross-link the chains into a two-dimensional extended structure. Although its precision is much poorer than for the other complexes in this series, this structure is clearly very similar to that of $\left[\operatorname{PdI}_{2}\left([9] \operatorname{aneS}_{3}\right)\right]$.

\subsubsection{Effect of pressure on the intramolecular S $\cdots$ Pt interaction}

The interaction between the axial sulfur $\mathrm{S} 1$ and the Pt1 shortens as the pressure increases, from 3.203(13) $\AA$ at ambient pressure to 2.969(13) $\AA$ at $69.7 \mathrm{kbar}$, a decrease of 0.234(18) $\AA$ (see Figure S20). In comparison, the equatorial Pt1-S4 and Pt1-S7 bonds show no statistically significant changes. The precision of this study is insufficient to determine whether there are any real changes in

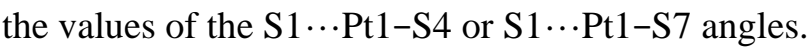

\subsubsection{Effects of pressure on the conformation of the macrocycle}

Within the high standard uncertainties on the torsion angles, the [234] conformation of the macrocycle is retained across the range of pressures studied (see Figure S21).

\subsubsection{Effects of pressure in the $S_{2} l_{2} P t$ equatorial plane}

There are no significant changes to the Pt1-I distances or to the position of Pt1 relative to the coordination plane in the pressure range studied.

\subsubsection{Effect of pressure on the intermolecular S $\cdots$ Pt interaction}

The length of the intermolecular interaction between the Pt1 and an equatorial sulfur atom S4\#1 (symmetry code: $\# 1=x+1 / 2,-y+1 / 2,1-z$ ), which forms part of a neighbouring molecule related by the $2_{1}$ screw axis parallel to $a$, decreases from 3.640(17) $\AA$ at ambient pressure to 3.154(16) $\AA$ at $69.7 \mathrm{kbar}$, a change of 0.49(2) $\AA$ (Figure S22). By ca. 5 kbar the distance has fallen below $\Sigma_{\mathrm{vdw}}$ for Pt and S (3.52 $\AA$ A; Bondi, 1964), at which point Pt1‥S4 interactions form chains of molecules within the structure and complete distorted octahedral coordination at Pt1. 


\subsubsection{Effects of pressure on iodide "iodide catenation}

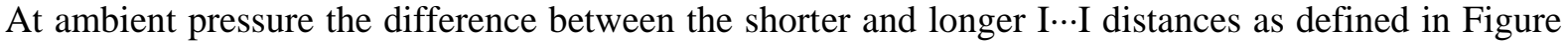
16 is $0.715(8) \AA$. As the pressure is increased to $69.7 \mathrm{kbar}$, the distances decrease to similar degrees, the shorter by $0.585(9) \AA$ and the longer by $0.531(8) \AA$, corresponding to reductions of $13.8 \%$ and $10.7 \%$, respectively (Figure S23). By $c a .16$ kbar the shorter distance has contracted sufficiently to bring it below $\Sigma_{\mathrm{vdw}}$ for two iodine atoms, and it continues to contract as pressure increases, at 69.7 kbar reaching 3.655(7) $\AA, 0.305(7) \AA$ within $\Sigma_{\text {vdw }}(3.96 \AA)$. The longer distance also contracts with increasing pressure, but even at $69.7 \mathrm{kbar}$ its length lies well beyond $\Sigma_{\mathrm{vdw}}$.

\subsection{Overview of catenation in $\left[M X_{2}\left([9] a n e S_{3}\right)\right]$ complexes}

At ambient pressure all six complexes $\left[M X_{2}\left([9] \mathrm{aneS}_{3}\right)\right], M=\mathrm{Pd}, \mathrm{Pt} ; X=\mathrm{Cl}, \mathrm{Br}, \mathrm{I}$, are isomorphous and isostructural. However, with the application of pressure the complexes do not all remain isostructural with each other. Within the extended structure of the crystal the dihalides have the potential to exhibit halogen $\cdots$ halogen interactions which generate sheets normal to the $c$ axis. Iodine is well-known to catenate, i.e., to form bonds or significant contacts with itself. In this section we explore the question of whether pressure can be used to instigate such catenation in the diiodide complexes and whether increased pressure can induce catenation in the dibromide and dichloride complexes, such that they form chains through $\mathrm{Br} \cdots \mathrm{Br}$ or $\mathrm{Cl} \cdots \mathrm{Cl}$ interactions, respectively.

The values of $\Sigma_{\mathrm{vdw}}$ for $\mathrm{Cl} \cdots \mathrm{Cl}, \mathrm{Br} \cdots \mathrm{Br}$ and I $\cdots \mathrm{I}$ are $3.50,3.70$ and $3.96 \AA$, respectively (Bondi, 1964). At ambient pressure none of the halogen $\cdots$ halogen distances lie within the corresponding $\Sigma_{\mathrm{vdw}}$, but by ca. $20 \mathrm{kbar}$ catenation is established for the diiodide complexes (see above and Table 7). Catenation appears in the dibromide complexes only at much higher pressures of $c a .58 \mathrm{kbar}$, an observation which suggests that the application of higher pressure can induce bromide to imitate the behaviour of iodide. As discussed below, no catenation is observed for the dichloride complexes in the pressure range studied.

The halogen $\cdots$ halogen interactions are of Type I, which are characterised by approximately similar M- $X \cdots X$ angles $\left(\theta_{1}\right.$ and $\theta_{2}$; see Table 8$)$ rather than Type II where one of these angles is close to $180^{\circ}$ and the other is near $90^{\circ}$ (Desiraju \& Parthasarathy, 1989). For the four dibromo and diiodo complexes the separation between $\theta_{1}$ and $\theta_{2}$ gradually reduces, from around $10^{\circ}$ at low pressures to half that value or less at the highest pressures studied. The shortening $X \cdots X$ contact distances and the converging of $\theta_{1}$ and $\theta_{2}$ are indicators of $X \cdots X$ interactions strengthening with increasing pressure.

Table 8 Details of the shorter $X \cdots X$ contact for the six $\left[M X_{2}\left([9] \mathrm{aneS}_{3}\right)\right]$ complexes $(M=\mathrm{Pd}, \mathrm{Pt} ; X=$ $\mathrm{Cl}, \mathrm{Br}, \mathrm{I}) . \theta_{1}$ and $\theta_{2}$ are the angles subtended at $X 1$ and $X 2$ in $\mathrm{M}-X 1 \cdots X 2-M$. 


\begin{tabular}{|c|c|c|c|c|c|c|}
\hline Complex & $\begin{array}{c}\text { Value at ambient } \\
\text { pressure/ } / \AA\end{array}$ & $\Sigma_{\mathrm{vdw}} / \AA$ & $\begin{array}{l}\text { Pressure at } \\
\sum_{\mathrm{vdw}} / \mathrm{kbar}\end{array}$ & $\begin{array}{c}\text { Final } \\
\text { distance/Å }\end{array}$ & Final $\theta_{1}, \theta_{2} /^{\circ}$ & $\begin{array}{c}\text { Final pressure } \\
\text { /kbar }\end{array}$ \\
\hline$\left[\mathrm{PdCl}_{2}\left([9] \mathrm{aneS}_{3}\right)\right]$ & $4.324(16)$ & 3.50 & 44 (see text) & $3.343(2)$ & $\begin{array}{l}139.6(5) \\
119.8(5)\end{array}$ & 76.8 \\
\hline$\left[\mathrm{PtCl}_{2}\left([9] \mathrm{aneS}_{3}\right)\right]$ & $4.310(2)$ & 3.50 & - & $3.759(5)$ & $\begin{array}{l}119.7(6) \\
110.6(6)\end{array}$ & 54.0 \\
\hline$\left[\operatorname{PdBr}_{2}\left([9] \mathrm{aneS}_{3}\right)\right]$ & $4.211(2)$ & 3.70 & 58 & $3.504(9)$ & $\begin{array}{l}118.9(2) \\
114.0(2)\end{array}$ & 116.9 \\
\hline$\left[\mathrm{PtBr}_{2}\left([9] \mathrm{aneS}_{3}\right)\right]$ & $4.1952(13)$ & 3.70 & 57 & $3.540(2)$ & $\begin{array}{l}115.5(2) \\
112.7(2)\end{array}$ & 97.1 \\
\hline$\left[\mathrm{PdI}_{2}\left([9] \mathrm{aneS}_{3}\right)\right]$ & $4.245(2)$ & 3.96 & 20 & $3.632(4)$ & $\begin{array}{l}118.7(2) \\
113.6(2)\end{array}$ & 94.0 \\
\hline$\left[\mathrm{PtI}_{2}\left([9] \mathrm{aneS}_{3}\right)\right]$ & $4.240(5)$ & 3.96 & 16 & $3.654(4)$ & $\begin{array}{l}115.4(4) \\
113.1(4)\end{array}$ & 69.7 \\
\hline
\end{tabular}

The behaviour of the $X \cdots X$ interactions in $\left[\mathrm{PdCl}_{2}\left([9] \mathrm{aneS}_{3}\right)\right]$ is unique and anomalous within the group of six complexes. Although both distances contract as expected between ambient pressure and 42.5 kbar, across the phase change at 44 kbar the shorter distance contracts by 0.294(9) $\AA$ [from 3.761(4) $\AA$ to $3.467(8) \AA$ ] , but the longer distance increases by $0.59(2) \AA$ [from 4.688(9) $\AA$ to 5.28(2) $\AA$ ] (Figure 19). Although the contraction brings the shorter $\mathrm{Cl} \cdots \mathrm{Cl}$ distance marginally below $\Sigma_{\mathrm{vdw}}(3.5$ $\AA$ ), increasing the pressure to $76.8 \mathrm{kbar}$ results in only minimal further contraction. This behaviour is related to trends in $\theta_{1}$ and $\theta_{2}$ which differ sharply from those seen for the dibromo and diiodo complexes: for $\left[\mathrm{PdCl}_{2}\left([9] \mathrm{aneS} \mathrm{S}_{3}\right)\right]$, with increasing pressure the values of these parameters diverge rather than converge. We conclude that the shortened contact is a consequence of the formation of the chains at $44 \mathrm{kbar}$ and does not represent catenation of chlorides. Coupled with the fact that we were unable to study $\left[\mathrm{PtCl}_{2}\left([9] \mathrm{aneS}_{3}\right)\right]$ beyond a pressure of $54.0 \mathrm{kbar}$, we cannot confidently identify catenation in either $\left[\mathrm{PdCl}_{2}\left([9] \mathrm{aneS}_{3}\right)\right]$ or $\left[\mathrm{PtCl}_{2}\left([9] \mathrm{aneS}_{3}\right)\right]$ across the pressure ranges studied.

\subsection{Density functional theory calculations}

\subsubsection{Introduction}

In parallel with the crystallographic investigations, density functional theory (DFT) calculations were performed on each high pressure crystal structure to estimate the effect of the structural changes on the total bonding, steric interaction and orbital interaction energies, and metal-ligand bond orders for each $\left[M X_{2}\left([9] \mathrm{aneS}_{3}\right)\right](M=\mathrm{Pd}, \mathrm{Pt} ; X=\mathrm{Cl}, \mathrm{Br}, \mathrm{I})$. For each complex at each pressure two symmetryequivalent molecules were generated to give a chain of three molecules $\left(\left[\mathrm{MX}_{2}\left([9] \mathrm{aneS} \mathrm{S}_{3}\right)\right]_{3}\right)$ along the direction of the intermolecular M $\cdots \mathrm{S} 4$ interaction. Metal ligand bond orders are reported for the central $\left[M X_{2}\left([9] \mathrm{ane} S_{3}\right)\right]$ complex in each chain of three molecules. 
We performed a bond energy analysis using the energy decomposition scheme as implemented in $\mathrm{ADF}$ in which the internal energy $\left(\Delta E_{\text {int }}\right)$ is calculated relative to the energies of the free atoms from which each model is constructed. The internal energy $\left(\Delta E_{\text {int }}\right)$ has contributions from the Pauli repulsions between the occupied orbitals $\left(\Delta E_{\text {Pauli }}\right)$ attractive electrostatic interactions $\left(\Delta E_{E l}\right)$ and orbital interactions $\left(\Delta E_{o i}\right)$ containing contributions from the donation of charge from the occupied orbitals of one fragment and the virtual orbitals of the other fragment and the mixing of occupied and virtual orbitals of the same fragment:

$\Delta E_{\text {int }}=\Delta E_{\text {Pauli }}+\Delta E_{E l}+\Delta E_{o i}$

Together $\Delta E_{\text {Pauli }}+\Delta E_{E l}$ comprise the steric interaction energy $\left(\Delta E^{0}\right)$ of the fragments.

There is a general trend for each $\left.\left[M X_{2}([9] \mathrm{aneS})_{3}\right)\right]_{3}(M=\mathrm{Pd}, \mathrm{Pt} ; X=\mathrm{Cl}, \mathrm{Br}, \mathrm{I})$ model by which $\Delta E_{\text {int }}$ increases with increasing pressure (Figure 20). Variations in $\Delta E_{\text {int }}$ for $\left[M \mathrm{I}_{2}\left([9] \mathrm{ane} \mathrm{S}_{3}\right)\right](M=\mathrm{Pd}, \mathrm{Pt})$ are ascribed to the limited precision of the crystal structure determinations which are the source of the atomic coordinates for the DFT calculations. In contrast to the general trend of $\Delta E_{\text {int }}$ increasing with pressure for $\left[M X_{2}\left([9] \mathrm{aneS}_{3}\right)\right]_{3}(M=\mathrm{Pd}, X=\mathrm{Br}$, I and $M=\mathrm{Pt}, X=\mathrm{Cl}, \mathrm{Br}, \mathrm{I}),\left[\mathrm{PdCl}_{2}\left([9] \mathrm{aneS}_{3}\right)\right]_{3}$ shows a feature across the phase transition involving a decrease in $\Delta E_{\text {int }}$ of $352 \mathrm{~kJ} \mathrm{~mol}^{-1}$ between 36 and 42.5 kbar and an increase in $\Delta E_{\text {int }}$ by $433 \mathrm{~kJ} \mathrm{~mol}^{-1}$ between 42.5 and $46 \mathrm{kbar}$ coincident with the phase transition. There is a continued increase in energy (by a further $130 \mathrm{~kJ} \mathrm{~mol}^{-1}$ ) up to $76.8 \mathrm{kbar}$.

\subsubsection{Steric interaction energies $\left(\Delta E^{0}\right)$}

The steric interaction energies $\left(\Delta E^{0}\right)$ for each complex are compared in Figure S24. At ambient pressure the $\mathrm{Pd}(\mathrm{II})$ complexes $\left[\mathrm{PdCl}_{2}\left([9] \mathrm{aneS}_{3}\right)\right]_{3},\left[\mathrm{PdBr}_{2}\left([9] \mathrm{aneS}_{3}\right)\right]_{3}$ and $\left[\mathrm{PdI}_{2}\left([9] \mathrm{aneS}_{3}\right)\right]_{3}$ possess lower $\Delta E^{0}$ than their $\operatorname{Pt}(\mathrm{II})$ counterparts by $c a .2500 \mathrm{~kJ} \mathrm{~mol}^{-1}$. As pressure is increased the trends follow those of the total bonding energy, with $\left[\mathrm{PtCl}_{2}\left([9] \mathrm{aneS}_{3}\right)\right]_{3}, \quad\left[\operatorname{PdBr}_{2}\left([9] \mathrm{aneS}_{3}\right)\right]_{3}$ and $\left[\operatorname{PtBr}_{2}\left([9] \operatorname{aneS}_{3}\right)\right]_{3}$ each showing an increase in $\Delta E^{0}$ with increasing pressure.

An increase in $\Delta E^{0}$ is consistent with the observed compressions of the unit cells for each complex, resulting in an increase in steric repulsion between each atomic fragment. For $\left[\operatorname{PdCl}_{2}\left([9] \operatorname{aneS}_{3}\right)\right]_{3} \Delta E^{0}$ increases in energy between 19.0 and $23.5 \mathrm{kbar}$ before decreasing in energy across the phase change. This suggests that the effects of the phase change, including the compression of the S1Pd1 and S4\#1 $\cdots$ Pd1 distances, displacement of the $\mathrm{Cl} 1$ out of the coordination plane and the rearrangement of the macrocycle could relieve the steric repulsion in the system.

\subsubsection{Orbital interaction energies $\left(\Delta E_{\mathrm{oi}}\right)$}

$\left[\operatorname{PtCl}_{2}\left([9] \mathrm{aneS}_{3}\right)\right]_{3}, \quad\left[\operatorname{PdBr}_{2}\left([9] \mathrm{aneS}_{3}\right)\right]_{3}$ and $\left[\operatorname{PtBr}_{2}\left([9] \mathrm{aneS}_{3}\right)\right]_{3}$ each follow the trend of increased pressure resulting in a more negative $\Delta E_{o i}$ (Figure $\left.\mathrm{S} 25\right)$. $\left[\mathrm{PdCl}_{2}\left([9] \mathrm{aneS}_{3}\right)\right]_{3}$ shows an initial decrease in energy before an increase of $c a .4900 \mathrm{~kJ} \mathrm{~mol}^{-1}$ between 23.5 and $42.5 \mathrm{kbar}$, indicating that $\Delta E_{\mathrm{oi}}$ are 
less favourable during the phase change than at lower pressures. Taking $\Delta E^{0}$ and $\Delta E_{o i}$ together it appears that the steric interactions between fragments dominates the variations in $\Delta E_{\mathrm{int}}$ in $\left[M X_{2}\left([9] \mathrm{aneS}_{3}\right)\right]_{3}(M=\mathrm{Pd}, \mathrm{Pt} ; X=\mathrm{Cl}, \mathrm{Br}, \mathrm{I})$.

\subsubsection{Bond orders in $\left[M X_{2}\left([9] a n e S_{3}\right)\right]_{3}$}

Mayer bond orders (Mayer 1983; Mayer, 1984) were calculated to compare the nature of the metalligand interactions about the $\mathrm{Pd}(\mathrm{II})$ or $\mathrm{Pt}(\mathrm{II})$ centre in the central molecule of each $\left[M X_{2}\left([9] \mathrm{ane} \mathrm{S}_{3}\right)\right]_{3}$ $(M=\mathrm{Pd}, \mathrm{Pt} ; X=\mathrm{Cl}, \mathrm{Br}, \mathrm{I})$ unit.

\subsubsection{Bond order for the axial S1 $\cdots M$ contact}

$\left[\operatorname{PtCl}_{2}\left([9] \mathrm{aneS}_{3}\right)\right],\left[\operatorname{PtBr}_{2}\left([9] \mathrm{aneS}_{3}\right)\right]$ and $\left[\operatorname{PtI}_{2}\left([9] \mathrm{aneS}_{3}\right)\right]$ have lower $\mathrm{S} 1 \cdots M$ bond orders than their palladium equivalents $\left[\operatorname{PdCl}_{2}\left([9] \operatorname{aneS}_{3}\right)\right],\left[\operatorname{PdBr}_{2}\left([9] \mathrm{aneS}_{3}\right)\right]$ and $\left[\operatorname{PdI}_{2}\left([9] \mathrm{aneS}_{3}\right)_{3}\right.$. The general trend (Figure 21) is that with increased pressure the bond order for the $M \cdots \mathrm{S} 1$ interaction increases steadily in all $\left.\left[M X_{2}[9] \mathrm{aneS}_{3}\right)\right]$ complexes. However, $\left.\left[\mathrm{PdCl}_{2}[9] \mathrm{aneS}_{3}\right)\right]$ shows a relatively large increase in bond order from 0.172 to 0.237 between 42.5 and $46 \mathrm{kbar}$, consistent with the sudden decrease in the S1 ...Pd1 distance from 3.009(5) to 2.849(7) $\AA$ at this pressure.

\subsubsection{Metal-halide bond orders}

The trends in the metal-halide bond orders are shown in Figures S26 and S27. General observations include variations in the $M-X$ bond order of $\mathrm{Br}<\mathrm{Cl}<\mathrm{I}$ which do not mirror the variations in the $M-$ $X 1$ bond distances $(M=\mathrm{Pd}, \mathrm{Pt} ; X 1=\mathrm{Cl}, \mathrm{Br}$, I; see Supplementary Molecular Geometry Information); bond distances in the $\mathrm{Pd}(\mathrm{II})$ complexes are shorter than in their $\mathrm{Pt}(\mathrm{II})$ counterparts and the halides follow the trend $\mathrm{Cl}<\mathrm{Br}<\mathrm{I}$. There is little change in the $\mathrm{Pd}-X 1$ bond order of $\left[\mathrm{PdCl}_{2}\left([9] \mathrm{aneS}_{3}\right)\right]$ over its phase change, despite the movement of $\mathrm{Cl} 1$ out of the coordination plane; there is little change in the bond order for any $M-X 2$ bond as pressure increases.

\subsubsection{Bond orders between the metal and equatorial sulfur atoms}

The calculations of the bond order between the metal and the equatorial sulfur atoms (Figures S28, S29) show no systematic variation, consistent with the observation that the metal-equatorial sulfur distances in $\left[M X_{2}\left([9] \operatorname{aneS}_{3}\right)\right](M=\mathrm{Pd}, \mathrm{Pt} ; X=\mathrm{Cl}, \mathrm{Br}, \mathrm{I})$ do not vary significantly as a function of pressure.

\subsubsection{Bond order for the intermolecular sulfur-metal contact in $\left[M X_{2}\left([9] a n e S_{3}\right)\right]_{3}$}

At ambient pressure the bond orders for the intermolecular $M \cdots \mathrm{S}$ interaction (Figure 22) are lower than those for the intramolecular $M \cdots \mathrm{S}$ axial interaction (Figure 21) and considerably lower than the bond orders for the equatorial $M-S$ bonds ( $c a .0 .8$ ). The bond order associated with the intermolecular 
$M \cdots \mathrm{S}$ interaction increases with pressure for all $\left[M X_{2}\left([9] \mathrm{aneS}_{3}\right)\right](M=\mathrm{Pd}, \mathrm{Pt} ; X=\mathrm{Cl}, \mathrm{Br}, \mathrm{I})$, consistent with the shortening of the S4\#1 $\cdots M 1$ distance (see Supplementary Information, Figure B2). For $\left[\mathrm{PdCl}_{2}\left([9] \mathrm{aneS}_{3}\right)\right]$ there is a significant increase in the $M \cdots \mathrm{S}$ bond order across the phase change as the intermolecular $M \cdots \mathrm{S}$ interaction shortens from 3.204(5) to 3.117(8) $\mathrm{A}$.

The calculated $M 1 \cdots$ S4\# bond orders reveal that each complex appears to exhibit a weak $M 1 \cdots \mathrm{S} 4 \#$ interaction at ambient pressure: 0.060 for $\left[\operatorname{PdCl}_{2}\left([9] \mathrm{aneS}_{3}\right)\right]$ and $\left[\operatorname{PdBr}_{2}\left([9] \mathrm{aneS}_{3}\right)\right], 0.045$ for $\left[\operatorname{PtCl}_{2}\left([9] \mathrm{aneS}_{3}\right)\right],\left[\operatorname{PtBr}_{2}\left([9] \mathrm{aneS}_{3}\right)\right]$ and $\left[\operatorname{PdI}_{2}\left([9] \mathrm{aneS}_{3}\right)\right]$, and 0.025 for $\left[\operatorname{PtI}_{2}\left([9] \mathrm{aneS}_{3}\right)\right]$. The larger $M \cdots \mathrm{S} 4 \#$ bond orders calculated for $\left[\mathrm{PdCl}_{2}\left([9] \mathrm{aneS}_{3}\right)\right]$ and $\left[\mathrm{PdBr}_{2}\left([9] \mathrm{aneS}_{3}\right)\right]$ at ambient pressure are attributed to the shorter Pd1 $\cdots$ S4\# distances, with the lower value for $\left[\mathrm{PtI}_{2}\left([9] \mathrm{aneS}_{3}\right)\right]$ attributed to the longer Pt $1 \cdots$ S4\# distance found at ambient pressure (see Supplementary Information, Figure B2).

As the pressure is increased, the $M \cdots \mathrm{S} 4 \#$ bond order in $\left[\mathrm{PdCl}_{2}\left([9] \mathrm{aneS}_{3}\right)\right]$ increases, reaching a value of 0.093 at 42.5 kbar before increasing sharply to 0.101 through the phase change at $44 \mathrm{kbar}$, then continuing to increase after $46 \mathrm{kbar}$ to reach a value of 0.116 at $76.8 \mathrm{kbar}$. Although similar increases in bond order with increasing pressure are observed for $\left[M X_{2}\left([9] \mathrm{aneS}_{3}\right)\right](M=\mathrm{Pd}, X=\mathrm{Br}, \mathrm{I}$ and $M=$ $\mathrm{Pt}, X=\mathrm{Cl}, \mathrm{Br}, \mathrm{I})$, none show any features related to a significant structural change. $\left[\mathrm{PtCl}_{2}\left([9] \mathrm{aneS}_{3}\right)\right]$ appears to reach a limit in bond order for the interaction at $c a .39$ kbar.

\subsubsection{Summary of DFT studies}

Single point gas phase DFT calculations on models of $\left[M X_{2}\left([9] \mathrm{aneS}_{3}\right)\right]_{3}(M=\mathrm{Pd}, \mathrm{Pt} ; X=\mathrm{Cl}, \mathrm{Br}, \mathrm{I})$ suggest that within these units $\Delta E_{\text {int }}$ is dominated by steric considerations, in line with the decrease in unit cell parameters for each complex. Trends in $M \cdots$ axial S, $M$-equatorial $\mathrm{S}$ and intermolecular $M \cdots{ }^{\cdots} \mathrm{S}$ bond orders with pressure for the central $\left[M X_{2}\left([9] \mathrm{aneS}_{3}\right)\right](M=\mathrm{Pd}, \mathrm{Pt} ; X=\mathrm{Cl}, \mathrm{Br}, \mathrm{I})$ also mirror the variation of geometrical parameters with pressure for each complex. Calculations on $\left[M X_{2}\left([9] \mathrm{aneS}_{3}\right)\right]_{3}$ corresponding to ambient pressure reveal a weak $M 1 \cdots \mathrm{S} 4 \#$ interaction that develops as the pressure is increased. Only those calculations carried out for $\left[\mathrm{PdCl}_{2}\left([9] \mathrm{aneS}_{3}\right)\right]_{3}$ predict significant changes in energy and bond orders: these correspond to the experimentally observed phase change in $\left[\mathrm{PdCl}_{2}\left([9] \mathrm{aneS}_{3}\right)\right]$ between 42.5 and $46 \mathrm{kbar}$. We are currently searching for other coordination complexes which show unusual behaviour under compression.

\section{Conclusions}

Although all exhibit contraction of both the intramolecular axial sulfur-metal interaction and the intermolecular equatorial sulfur-metal interaction to yield a chain polymer with distorted octahedral co-ordination at the metal centre, the six members of the family of $\mathrm{Pd}(\mathrm{II})$ complexes $\left[M X_{2}\left([9] \mathrm{ane} \mathrm{S}_{3}\right)\right]$ 
$\left(M=\mathrm{Pd}, \mathrm{Pt} ; X=\mathrm{Cl}, \mathrm{Br}, \mathrm{I} ;\right.$ [9] $\mathrm{aneS}_{3}=1,4,7$-trithiacyclononane) otherwise fall into three distinct groups:

(i) $\left[\mathrm{PdCl}_{2}\left([9] \mathrm{aneS}_{3}\right)\right]$ uniquely undergoes a phase change between 42.5 and 46 kbar to yield an intensely black product and an unprecedented [1233] conformation for the thioether ligand;

(ii) the three complexes $\left[\operatorname{PtCl}_{2}\left([9] \operatorname{aneS}_{3}\right)\right],\left[\operatorname{PdBr}_{2}\left([9] \operatorname{aneS}_{3}\right)\right]$ and $\left[\operatorname{PtBr}_{2}\left([9] \operatorname{aneS}_{3}\right)\right]$ show no other significant changes until $\mathrm{Br}$ * $\mathrm{Br}$ interactions become significant for the two dibromo complexes at around 58 kbar;

(iii) the diiodo complexes $\left[\operatorname{PdI}_{2}\left([9] \mathrm{aneS}_{3}\right)\right]$ and $\left[\mathrm{PtI}_{2}\left([9] \mathrm{aneS}_{3}\right)\right]$ exhibit pressure-induced $\mathrm{I}^{\cdots} \mathrm{I}$ interactions at around $20 \mathrm{kbar}$.

In contrast to the significant changes in the lengths of the intramolecular and intermolecular sulfurmetal interactions, the geometric changes within the $\mathrm{S}_{2} X_{2} M$ equatorial plane, if any, are relatively minor and follow no consistent trends.

It is striking that only one of the six isomorphous compounds in this study displays an abrupt phase change upon the application of pressure. Each compound is set up for a change from fourcoordination of the central metal to six-coordination, but only $\left[\mathrm{PdCl}_{2}\left([9] \mathrm{aneS}_{3}\right)\right]$ undergoes a distinct structural change. The metal ions $\mathrm{Pd}(\mathrm{II})$ and $\mathrm{Pt}(\mathrm{II})$ are both well known for their strong preference for square planar geometry, with six-coordinate complexes of the $4 d$ ion $\operatorname{Pd}($ II) being relatively rare: excluding complexes exhibiting metal-metal interactions, for Pt there are 11580, 2698 and 1501 occurrences of four-, five- and six-coordinate complexes, respectively, while for Pd the corresponding numbers are 14086, 1739 and only 135 (Allen, 2002; CSD version 5.34 November 2012 plus three updates). The halides become more polarisable as their size increases and in turn they become better $\pi$-donors. Thus, the ligand field stabilisation of the six-coordinate species will be greater with chloride than with bromide or iodide. Complementary to this is the effect of the increasing covalency of the halides: as size increases there is more effective $\pi$-donation to the metal which will reduce any partial positive charge at the metal centre (electroneutrality principle). These two effects favour the adoption of a six-coordinate geometry by $\left[\mathrm{PdCl}_{2}\left([9] \mathrm{aneS}_{3}\right)\right]$. Furthermore, the formation of short $\mathrm{I} \cdots \mathrm{I}$ and $\mathrm{Br} \cdots \mathrm{Br}$ interactions in the diiodo and dibromo complexes will potentially have an impact on the subtle energetics of the system.

Acknowledgements We are grateful to the University of Nottingham and to EPSRC for funding, including a Next Generation Facility Users Panel Award by the latter, and to STFC and Diamond Light Source for the award of beamtime at Daresbury SRS Station 16.2SMX and Diamond Beamline I19, respectively. NRC gratefully acknowledges receipt of a Royal Society Wolfson Merit Award. MS acknowledges receipt of an ERC Advanced Grant. We thank the referees for their perceptive and helpful comments. 


\section{References}

Agilent (2011). CrysAlis Pro, Agilent Technologies, Yarnton, England, UK.

Allan, D. R., Blake, A. J., Huang, D., Prior, T. J. \& Schröder, M. (2006). Chem. Commun. 4081-4083.

Allen, F. H. (2002). Acta Cryst. B58, 380-388.

Angel, R. J., Gonzalez-Platas, J. \& Alvaro, M. (2014). Z. Krist. DOI:10.1515/zkri-2013-1711.

Barnett, J. D., Block, S. \& Piermarini, G. J. (1973). Rev. Sci. Instrum. 44, 1-9.

Becke, A. D. (1988). Phys. Rev. A 38, 3098-3100.

Blake, A.J., Holder, A.J., Hyde, T. I., Roberts, Y. V., Lavery, A. J. \& Schröder, M. (1987).

J. Organometal. Chem. 323, 261-270.

Blake, A.J., Holder, A.J., Roberts, Y.V. \& Schröder, M. (1988). Acta Cryst. C44, 360-361.

Blake, A. J., Roberts, Y. V. \& Schröder, M. (1996). Dalton Trans., 1885-1895.

Bondi, A. (1964). J. Phys. Chem. 68, 441-452.

Byrne, P. J., Richardson, P. J., Chang, J., Kusmartseva, A. F., Allan, D. R., Jones, A. C., Kamenev, K. V., Tasker, P. A. \& Parsons, S. (2012). Chem. - Eur. J. 18, 7738-7748.

Granier, T., Gallious, B., Gualtier, J., Real, A. J. \& Zarembowitch, J. (1993). Inorg. Chem. 32, 53055312.

Dale, J. (1973). Acta Chem. Scand. 27, 1115-1129.

Desiraju, G. R. \& Parthasarathy, R. (1989). J. Am. Chem. Soc. 111, 8725-8726.

Flack, H. D. (1983). Acta Cryst. A39, 876-881.

Fonseca-Guerra, C., Snijders, J. G., Te Velde, G. \& Baerends, E. J. (1998). Theor. Chem. Acc. 99, 391-403.

Grant, G. J., Brandow, C. G., Galas, D. F., Davis, J. P., Pennington, W. T., Valente, E. J. \&

Zubkowski, J. D. (2001). Polyhedron 20, 3333-3342.

Guionneau, P., Gaultier, J., Rahal, M., Bravic, G., Mellado, J. M., Chasseau, D., Ducasse, L.,

Holzapfel, W. B. (2003). J. Appl. Phys. 93, 1813-1818.

Kurmoo, M. \& Day, P. (1995). J. Mater. Chem. 5, 1639-1645.

Mayer, I. (1983). Chem. Phys. Lett. 97, 270-274.

Mayer, I. (1984). Int. J. Quantum Chem. 26, 151-154.

Moggach, S. A., Galloway, K. W., Lennie, A. R., Parois, P., Rowantree, N., Brechin, E. K., Warren, J.

E., Murrie, M. \& Parsons, S. (2009). CrystEngComm 11, 2601-2604.

Okano, Y., Adach, T., Narymbetoz, B., Kobayashi, H., Zhou, B. \& Kobayashi, A. (2004). Chem. Lett. 33, 938-939.

Parois, P., Moggach, S. A., Benitez, J. S., Kamenev, K. V., Lennie, A. R., Warren, J. E., Brechin, E.

K., Parsons, S. \& Murrie, M. (2010). Chem. Commun. 46, 1881-1883.

Perdew, J. P. (1986). Phys. Rev. B 33, 8822-8824. 
Prescimone, A., Milios, C. J., Benitez, J. S., Kamenev, K. V., Loose, C., Kortus, J., Moggach, S. A., Murrie, M., Warren, J. E., Lennie, A. R., Parsons, S. \& Brechin, E. K. (2009). Dalton Trans., 48584867.

Prescimone, A., Milios, C. J., Moggach, S. A., Warren, J. E., Lennie, A.R., Benitez, J. S., Kamenev, K. V., Bircher, R., Murrie, M., Parsons, S. \& Brechin, E. K. (2008). Angew. Chem. Int. Ed. 47, 28282831.

Rahal, M., Chasseau, D., Gaultier, J., Ducasse, L., Kurmoo, M. \& Day, P. (1997). Acta Cryst. B53, 159-167.

Sheldrick, G. M. (2004). SADABS. University of Göttingen, Germany.

Sheldrick, G. M. (2008). Acta Cryst. A64, 112-122.

Slebodnick, C., Zhao, J., Angel, R. J., Hanson, B. E., Song, Y., Liu, Z. X. \& Hemley, R. J. (2004).

Inorg. Chem. 43, 5245-5252.

Takamizawa, S., Nakata, E. \& Miyake, R. (2009). Dalton Trans., 1752-1760.

Takamizawa, S. \& Kohbara, M. (2007). Dalton Trans., 3640-3645.

Takamizawa, S., Nakata, E., Saito, T. \& Akatsata, T. (2005). Inorg. Chem. 44, 1362-1366.

Te Velde, G., Bickelhaupt, F. M., Van Gisbergen, S. J. A.,Fonseca-Guerra, E. J. Baerends, S. J. A., Snijders, J. G. \& Ziegler, T. (2001). J. Comput. Chem. 22, 931-967.

Tidey, J. P., Wong, H. L. S., Schröder, M. \& Blake, A. J. (2014). Coord. Chem. Rev., DOI: 10.1016/j.ccr.2014.04.004, in press.

Vosko, S. H., Wilk, L. \& Nusair, M. (1980). Can. J. Phys. 58, 1200-1211.

Wieghardt, K., Küppers, H.-J., Raabe, E. \& Krüger, C. (1986). Angew. Chem. Int. Ed. 25, 1101-1103.

Wong, H. L. S., Allan, D. R., Champness, N. R., McMaster, J., Schröder, M. \& Blake, A. J. (2013). Angew. Chem. Int. Ed. 52, 5093-5095. 


\section{Figure captions}

Figure 1 Pressure dependence of the unit cell parameters for $\left[\mathrm{PdCl}_{2}\left([9] \mathrm{aneS}_{3}\right)\right]$. Note the crossover of the $b$ and $c$ axes at $44 \mathrm{kbar}$, which was confirmed by refinement of the structures. The error bars are smaller than the symbols.

Figure 2 Ball-and-stick representation of the structure of $\left[\mathrm{PdCl}_{2}\left([9] \mathrm{aneS}_{3}\right)\right]$ at ambient pressure showing the atom numbering scheme used.

Figure 3 Variation in the axial $\mathrm{S} 1 \cdots \mathrm{Pd} 1$ distance with increasing pressure for $\left[\mathrm{PdCl}_{2}\left([9] \mathrm{aneS}_{3}\right)\right]$.

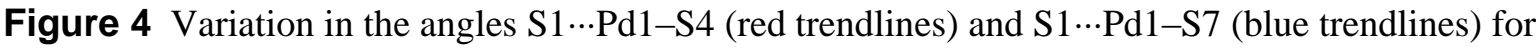
$\left[\mathrm{PdCl}_{2}\left([9] \mathrm{aneS}_{3}\right)\right]$, indicating the change in position of the axial sulfur donor atom $\mathrm{S} 1$ relative to $\mathrm{S} 4$, S7 and Pd1. Note that these changes occur largely over the narrow pressure range 42.5-46 kbar; the data points to either side of $44 \mathrm{kbar}$ are indicated by different symbols.

Figure 5 Variation of the displacement of Pd1 from the plane defined by S4, S7 and Cl2 with increasing pressure for $\left[\mathrm{PdCl}_{2}\left([9] \mathrm{aneS}_{3}\right)\right]$.

Figure 6 Pressure dependence of the torsion angles of the macrocyclic ring in $\left[\mathrm{PdCl}_{2}\left([9] \mathrm{aneS}_{3}\right)\right]$, showing that major changes of $40-60^{\circ}$ occur in six of the nine torsion angles at $44 \mathrm{kbar}$. Standard uncertainties are in the range $1-5^{\circ}$ and error bars have been suppressed for clarity.

Figure 7 The change in conformation for $\left[\mathrm{PdCl}_{2}\left([9] \mathrm{aneS}_{3}\right)\right]$ between ambient pressure (a) and 76.8 kbar (b), showing the more symmetrical position of S1, the flattening of the S4-C5-C6-S7 region and the movement of $\mathrm{C} 8$.

Figure 8 Pressure dependence of the length of the intermolecular Pd1 $\cdots$ S4\#1 interaction in $\left[\mathrm{PdCl}_{2}\left([9] \mathrm{aneS}_{3}\right)\right]$.

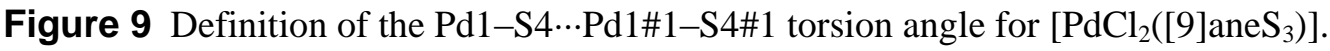

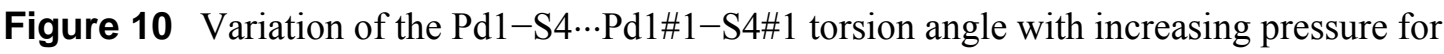
$\left[\mathrm{PdCl}_{2}\left([9] \mathrm{aneS}_{3}\right)\right]$.

Figure 11 Variation of selected valence angles subtended at Pd1 with increasing pressure for $\left[\mathrm{PdCl}_{2}\left([9] \mathrm{aneS}_{3}\right)\right]$.

Figure 12 Ball-and-stick representation of the structure of $\left[\mathrm{PtCl}_{2}\left([9] \mathrm{aneS}_{3}\right)\right]$ at ambient pressure showing the atom numbering scheme used. 
Figure 13 Ball-and-stick representation of the structure of $\left[\operatorname{PdBr}_{2}\left([9] \mathrm{aneS}_{3}\right)\right]$ at ambient pressure showing the atom numbering scheme used.

Figure 14 Ball-and-stick representation of the structure of $\left[\mathrm{PtBr}_{2}\left([9] \mathrm{aneS}_{3}\right)\right]$ at ambient pressure (Grant et al., 2001) showing the atom numbering scheme used. Note the disposition of the S4-C5C6-S7 linkage, indicative of the adoption of the opposite enantiomer to that seen in the structures $\left[\mathrm{PdCl}_{2}\left([9] \mathrm{aneS}_{3}\right)\right],\left[\mathrm{PtCl}_{2}\left([9] \mathrm{aneS}_{3}\right)\right]$ and $\left[\mathrm{PdBr}_{2}\left([9] \mathrm{aneS}_{3}\right)\right]$.

Figure 15 Ball-and-stick representation of the structure of $\left[\mathrm{PdI}_{2}\left([9] \mathrm{ane} \mathrm{S}_{3}\right)\right]$ at ambient pressure showing the atom numbering scheme.

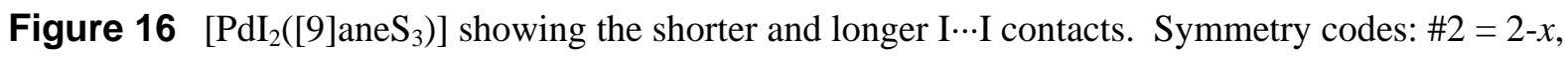
$y+1 / 2,-\mathrm{z}+\frac{3}{2} / 2 ; \# 3=x-1, y, z ; \# 4=x+1, y, z ; \# 5=2-x, y-1 / 2,{ }^{3} / 2-z$. Hydrogen atoms have been omitted for clarity.

Figure 17 Three views of the extended structure of $\left[\operatorname{PdI}_{2}\left([9] \mathrm{aneS}_{3}\right)\right]$ showing (a) a chain of molecules linked by the S $\cdots P d$ interactions common to all six complexes; (b) a view along the $a$-axis emphasising the I' I contacts; (c) a view along the $c$-axis showing layers of molecules linked by S $\cdots \mathrm{Pd}$ and I $\cdots \mathrm{I}$ contacts.

Figure 18 Ball-and-stick representation of the structure of $\left[\mathrm{PtI}_{2}\left([9] \mathrm{ane} \mathrm{S}_{3}\right)\right]$ at ambient pressure showing the atom numbering scheme used.

Figure 19 Variation of the shorter and longer $\mathrm{Cl} \cdots \mathrm{Cl}$ distances for $\left[\mathrm{PdCl}_{2}([9] \mathrm{aneS})\right.$. The horizontal black line indicates $\Sigma_{\mathrm{vdw}}$ at $3.5 \AA$ A. Note the anomalous behaviour of both $\mathrm{Cl} \cdots \mathrm{Cl}$ distances.

Figure 20 Total interaction energies in $\left[M X_{2}\left([9] \mathrm{aneS}_{3}\right)\right]_{3}$, where $\mathrm{PdCl} 2=\left[\mathrm{PdCl}_{2}\left([9] \mathrm{aneS}_{3}\right)\right]_{3}, \mathrm{PtCl} 2$ $=\left[\mathrm{PtCl}_{2}\left([9] \mathrm{anes}_{3}\right)\right]_{3}, \mathrm{PdBr} 2=\left[\mathrm{PdBr}_{2}\left([9] \mathrm{aneS}_{3}\right)\right]_{3}, \mathrm{PtBr} 2=\left[\mathrm{PtBr}_{2}\left([9] \mathrm{aneS}_{3}\right)\right]_{3}, \mathrm{PdI} 2=\left[\mathrm{PdI}_{2}\left([9] \mathrm{aneS}_{3}\right)\right]_{3}$ and PtI2 $\left.=\left[\mathrm{PtI}_{2}\left([9] \mathrm{aneS}_{3}\right)\right]_{3}\right)$. In $\left[\mathrm{PdCl}_{2}\left([9] \mathrm{aneS}_{3}\right)\right]_{3}$ the feature at $44 \mathrm{kbar}$ coincides with the observed phase transition.

Figure 21 Bond orders for the $\mathrm{S} 1 \cdots M 1(M=\mathrm{Pd}, \mathrm{Pt})$ interactions in $\left[M X_{2}\left([9] \mathrm{ane} \mathrm{S}_{3}\right)\right]_{3}$, where $\mathrm{PdCl} 2$ $=\left[\mathrm{PdCl}_{2}\left([9] \mathrm{aneS}_{3}\right)\right]_{3}, \mathrm{PtCl} 2=\left[\mathrm{PtCl}_{2}\left([9] \mathrm{anes}_{3}\right)\right]_{3}, \mathrm{PdBr} 2=\left[\mathrm{PdBr}_{2}\left([9] \mathrm{aneS}_{3}\right)\right]_{3}, \mathrm{PtBr} 2=$ $\left[\operatorname{PtBr}_{2}\left([9] \mathrm{aneS}_{3}\right)\right]_{3}, \operatorname{PdI} 2=\left[\operatorname{PdI}_{2}\left([9] \mathrm{aneS}_{3}\right)\right]_{3}$ and PtI2 $\left.=\left[\operatorname{PtI}_{2}\left([9] \mathrm{aneS}_{3}\right)\right]_{3}\right) . \operatorname{In}\left[\operatorname{PdCl}_{2}\left([9] \operatorname{aneS}_{3}\right)\right]_{3}$ the feature at $44 \mathrm{kbar}$ coincides with the phase transition.

Figure 22 Bond orders for the intermolecular S4\#1 $\cdots M(M=\mathrm{Pd}, \mathrm{Pt})$ interactions $\left[M X_{2}\left([9] \mathrm{ane} \mathrm{S}_{3}\right)\right]_{3}$, where $\mathrm{PdCl} 2=\left[\mathrm{PdCl}_{2}\left([9] \mathrm{aneS}_{3}\right)\right]_{3}, \mathrm{PtCl} 2=\left[\mathrm{PtCl}_{2}\left([9] \mathrm{anes}_{3}\right)\right]_{3}, \mathrm{PdBr} 2=\left[\mathrm{PdBr}_{2}\left([9] \mathrm{aneS}_{3}\right)\right]_{3}, \mathrm{PtBr} 2=$ $\left[\operatorname{PtBr}_{2}\left([9] \mathrm{aneS}_{3}\right)\right]_{3}, \operatorname{PdI} 2=\left[\operatorname{PdI}_{2}\left([9] \mathrm{aneS}_{3}\right)\right]_{3}$ and $\left.\operatorname{PtI} 2=\left[\operatorname{PtI}_{2}\left([9] \mathrm{aneS}_{3}\right)\right]_{3}\right)$. 